\title{
A Rotating Cylinder Method for Measuring Normal Spectral Emittance of Ceramic Oxide Specimens From 1200 to $1600{ }^{\circ} \mathrm{K}$
}

\author{
Howard E. Clark and Dwight G. Moore \\ Institute for Basic Standards, National Bureau of Standards, Washington, D.C. 20234
}

(June 10, 1966)

\begin{abstract}
Equipment was designed and constructed for measuring the spectral emittance of polycrystalline ceramic oxide specimens in the wavelength region 1 to $15 \mu$ and at temperatures of 1200,1400 , and $1600^{\circ} \mathrm{K}$. Specimens consisted of small hollow cylinders that were rotated at $100 \mathrm{rpm}$ in a furnace cavity equipped with a water-cooled viewing port. Emittances were determined by comparing the radiance of the specimen to that of a blackbody at the same temperature.

A series of six measurements (two measurements each on three specimens) was made on commercially pure specimens of alumina, thoria, magnesia, and zirconia. All four materials showed similar behavior in that the emittances were low in the shorter wavelength regions and high at the longer wavelengths. The temperature coefficients of spectral emittance were positive for all four materials, but varied with the material; those for thoria were appreciably higher than the other three. In all cases coefficients were greater at short wavelengths than at long.

Error sources were investigated, and the measurement uncertainties associated with each source were evaluated. It was concluded that at $1200^{\circ} \mathrm{K}$ the true values of emittance at $2 \mu$ for the particular specimens measured might be as much as 0.032 lower or 0.012 higher than the reported values. The data were in good agreement with reflectance measurements of the same material and with recently reported absorption coefficients.
\end{abstract}

Key Words: Alumina, ceramic oxides, emittance, error sources, magnesia, measurement uncertainties, spectral emittance, thermal radiation, thoria, zirconia.

Page

1. Introduction...................................... 394

2. Rotating specimen method............................ 394

2.1 Selection of method................................ 394

2.2 Rotational speed of specimens...................... 395

3. Equipment.......................................... $\quad 395$

3.1 Specimen furnace ........................... $\quad 395$

3.2 Blackbody furnaces............................... $\quad 396$

a. Details of construction........................ 396

3.3 Temperature control systems....................... 398

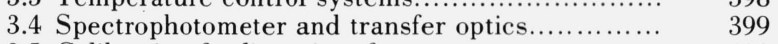

3.5 Calibration for linearity of response................. 400

4. Measurement procedure................................ 400

5. Discussion of errors.................................... 402

5.1 Transfer optics.................................... 402

a. Atmospheric absorption.................... 402

b. Preferential mirror absorption................... 402

5.2 Extraneous transmitted and reflected radiation... 402 a. Nonopacity of specimen wall............... 402 b. Furnace radiation reflected into specimen Page beam.......................................... 402

5.3 Errors from temperature uncertainties................. 403

5.4 Random error of measurement...................... 405

5.5 Estimated accuracy........................... 405

6. Measurements on polycrystalline oxide specimens....... 405

6.1 Description of specimens....................... 405

6.2 Results and discussion............................. 406

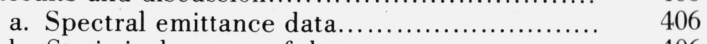

b. Statistical scatter of data....................... 406

c. Lack of stability of zirconia specimens.......... 409

d. Effect of temperature on emittance.............. 410

e. Comments on use of data for heat transfer computations.....

f. Correlation of data for alumina with reported absorption coefficients....................... 413

7. Summary ............................................... 414

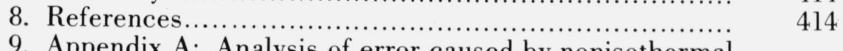

9. Appendix A: Analysis of error caused by nonisothermal blackbody furnace...................... 


\section{Introduction}

Knowledge of the spectral emittance ${ }^{1}$ of ceramic oxides at high temperatures is important, not only because of the many potential space applications for materials of this type, but also to obtain an improved understanding of the thermal emission mechanism in solids. Several investigators have made spectral emittance measurements on oxide materials; however, wide variations in the data are evident, especially in the shorter wavelength regions.

The lack of better agreement may be due, at least in part, to certain measurement problems that exist when determining the emittance of ceramic specimens. Three of the more important of these problems are

(A) Temperature gradients in specimens. Sizable temperature gradients are generated when a stationary ceramic oxide specimen is heated to a high temperature in such a way that it is free to radiate from an exposed surface. These gradients, which result from the low thermal conductivity of the material, create serious measurement problems. The radiation emitted from a ceramic oxide specimen originates not only from the outermost surface layer, as it does for metals, but also from volume elements at appreciable distances below the surface. Hence, when a gradient is present it becomes virtually impossible to assign a unique temperature to the source of the emitted radiation, and without a knowledge of this temperature, a reliable emittance measurement becomes impossible.

(B) Extraneous reflected radiation. Polycrystalline ceramic specimens are known to reflect thermal radiation diffusely rather than specularly. This means that any thermal radiation striking the viewed area of the specimen, regardless of the angle of incidence, will be diffusely reflected with some of it entering the specimen beam to give high values of emittance. Thus, unless elaborate precautions are taken to exclude this diffusely reflected radiation, for instance from furnace walls, measurements can be high by sizable amounts. This source of error becomes especially critical with ceramic specimens in the shorter wavelength regions where reflectance often exceeds 0.90 .

(C) Extraneous transmitted radiation. Many single crystal oxides, such as sapphire, have a very high transmittance for radiation in the near infrared. However, when the same oxides are finely ground and then bonded by high temperature sintering, the material becomes less transparent because of internal scattering effects (multiple internal reflections at interfaces) and in this way it is sometimes possible to prepare polycrystalline specimens that will be substantially opaque to radiation in the near infrared at thicknesses as low as $1 / 4$ in. If the specimen to be measured is not opaque, then serious errors will

\footnotetext{
${ }^{1}$ As used in this paper, emittance is the ratio of energy radiated by a specimen per unit time and per unit area to that from a blackbody at the same temperature and under the same conditions. The conditions refer to the geometric and spectral distribution of the same conditions.
radiated energy.
}

result due to radiation from the furnace enclosure passing through the specimen and entering the specimen beam.

A rotating specimen method was chosen for the investigation described herein, since this approach minimizes temperature gradients in specimens. The present report begins by describing the earlier applications of this method. Subsequent sections include a description of the equipment and the measurement procedure, a detailed discussion of errors, and, finally, the results of spectral measurements for polycrystalline specimens of alumina, thoria, magnesia, and zirconia at 1200,1400 , and $1600{ }^{\circ} \mathrm{K}$.

The investigation was conducted at the National Bureau of Standards. However, it was carried forward under the sponsorship and with the financial assistance of the National Aeronautics and Space Administration.

\section{Rotating Specimen Method}

\subsection{Selection of Method}

A review of earlier methods used to measure the emittance of nonmetals indicated that one of the best approaches for reducing temperature gradients in a ceramic specimen to workable levels is to move the heated specimen past a water-cooled viewing port. In this way, a freshly heated surface of the material is continuously arriving at the port for measurement. If the movement is sufficiently rapid, a thermal equilibrium is approached in which temperature gradients in the specimen approach minimal values.

The moving specimen concept was first introduced by Féry in 1902 [1]. ${ }^{2}$ In his measurements, and also in those made by Michaud [2] and Pattison [3], cylindrical specimens were rotated while being heated in a gas flame. The ratio of the radiant flux from the surface to that from a hole placed axially at the center of the specimen was then taken as the emittance. No viewing port was used. In other measurements, specimens were rotated in a furnace cavity that was equipped with a water-cooled viewing port. McMahon [4], Slemp and Wade [5], and Olsen and Katz [6], all used a semicircular disk-shaped specimen that was rotated in front of a viewing port so that blackbody radiation from the furnace struck the detector for one-half the cycle, and the detector saw radiation from the specimen for the remaining onehalf cycle. Both McMahon [4] and Olsen and Katz [6] arranged for the periodic insertion of a watercooled shutter behind the specimen so that it was possible, at least in theory, to determine the transmittance of the specimen material. Folweiler [7] described a rotating cylinder apparatus, which incorporated solid cylindrical specimens with a " $\mathrm{V}$ "

\footnotetext{
${ }^{2}$ Figures in brackets indicate the literature references on page 414
} 
groove positioned around the circumference to serve as a reference blackbody. The specimens were heated in a furnace with silicon carbide heating elements. A water-cooled viewing port was used.

In measurements made by Clayton [8] a horizontal disk-shaped specimen was rotated in a carbon-resistance furnace that was equipped with separate water-cooled viewing ports for detecting radiation from both the specimen and the furnace enclosure. The specimen sighting tube could be moved to two positions. In the first position, the region behind the viewed portion was the hot furnace enclosure, and in the second, it was a water-cooled baffle. Here, again, the aim was to measure both emittance and transmittance.

A careful consideration of the possible errors and of the expected experimental difficulties inherent in each of these methods resulted in the selection for the present measurements of a rotating-cylinder approach with a separate blackbody. Briefly stated, the method consisted of rotating a hollow cylindrical specimen, approximately 1 in in diameter by 1 -in high with $3 / 16$-in thick walls, in a wire-wound furnace equipped with a water-cooled viewing port. Spectral emittance measurements were then made with a double-beam spectrophotometer by comparing the radiance of the rotating specimen to that of a blackbody at the same temperature.

An earlier description of the measurement method has been published [9]. However, only preliminary data at one temperature $\left(1200{ }^{\circ} \mathrm{K}\right)$ where given at that time. Also, there was no systematic analysis of errors, since this phase of the investigation had not been completed at the time of the earlier publication.

\subsection{Rotational Speed of Specimens}

A theoretical analysis of periodic heat flow in a specimen rotating before a viewing port, performed as a first phase of the study, has been published by Peavy and Eubanks [10]. The analysis showed that at low rotational speeds the surface temperature of a specimen at the center of the viewing port opening will be substantially lower than the temperature of the thermocouple in the specimen cavity. However, this difference will decrease with increasing speed. The speed at which the difference will become negligibly small will depend on system geometry, thermal properties of the specimen material, and a derived average heat flux for the portion of the cycle during which a point on the specimen is being heated by the furnace.

This analytical treatment may be used to compute the rotational speed required to reduce radial temperature gradients in the specimen to acceptable levels. However, since reliable thermal property data are not presently available for the specimen materials, such computations can be of only limited value. Therefore, in the present work, the minimum permissible speed of rotation was determined experimentally by first rotating a specimen at a very low speed and measuring its emittance at $1.4 \mu .^{3}$ As the speed was increased, the indicated emittance at 1.4 $\mu$ continued to rise until a point was reached where further increases in speed caused no further increase in the measured emittance. For the materials studied in this report, the maximum value of emittance was reached at about $50 \mathrm{rpm}$. However, as an added insurance against possible errors, actual emittance measurements were made at $100 \mathrm{rpm}$.

\section{Equipment}

\subsection{Specimen Furnace}

Figure 1 is a schematic drawing of the specimen furnace. The high-temperature alumina core surrounding the specimen was wound with 0.032 -in-diam platinum-40 percent rhodium wire. The winding was continuous to the edges of the rectangular opening that was cut into the core to permit entrance of the viewing port. A booster winding of the same wire positioned on the outer alumina core, as indicated in the figure, was used to compensate for the large heat losses at the center.

The water-cooled viewing port was machined from copper, and its inner surface was curved to the same radius as the specimen. A shield of platinum foil, 0.002 -in thick, surrounded the outer surfaces of the port, including the edges that faced the specimen. This helped to thermally isolate the viewing port from the furnace interior. The inner surfaces of the viewing port and the portion of the platinum shield nearest the specimen were blackened to minimize the possibility of errors from reflected radiation. The opening at the inner end of the port was $1 / 8$-in wide by $1 / 2$-in high.

The specimens were prepared so as to be cylindrical to $\pm 0.002 \mathrm{in}$. The alumina support tube (fig. 1) was surface ground to this same tolerance. The spindle was driven by a $1 / 8$ HP motor that was coupled to a gear reducer. With the arrangement used, the rotation of the specimen could be adjusted to any speed in the range 1 to $300 \mathrm{rpm}$.

The design of the furnace shell was such that the furnace could be operated in an inert atmosphere, as well as in air. Glass-metal seals were used for power leads and "O"-ring seals were used for the shell ends, as well as for a sodium chloride viewing windows. The thrust bearings were designed to provide a reasonably gas-tight seal at the point where the spindle shaft entered the shell. Although this controlled-atmosphere feature had been incorporated into the design, all measurements included in this report were made in air with no windows. Also, although the furnace was capable of being operated at $1800^{\circ} \mathrm{K}$, no measurements were made at this temperature, because of temperature control difficulties (see sec. 3.3).

\footnotetext{
${ }^{3}$ Difference in temperature between specimen and blackbody has the greatest effect on emittance at wavelengths below the energy peak of blackbody radiation. The selected setting of $1.4 \mu$ is well below this peak for the selected test temperatures.
} 


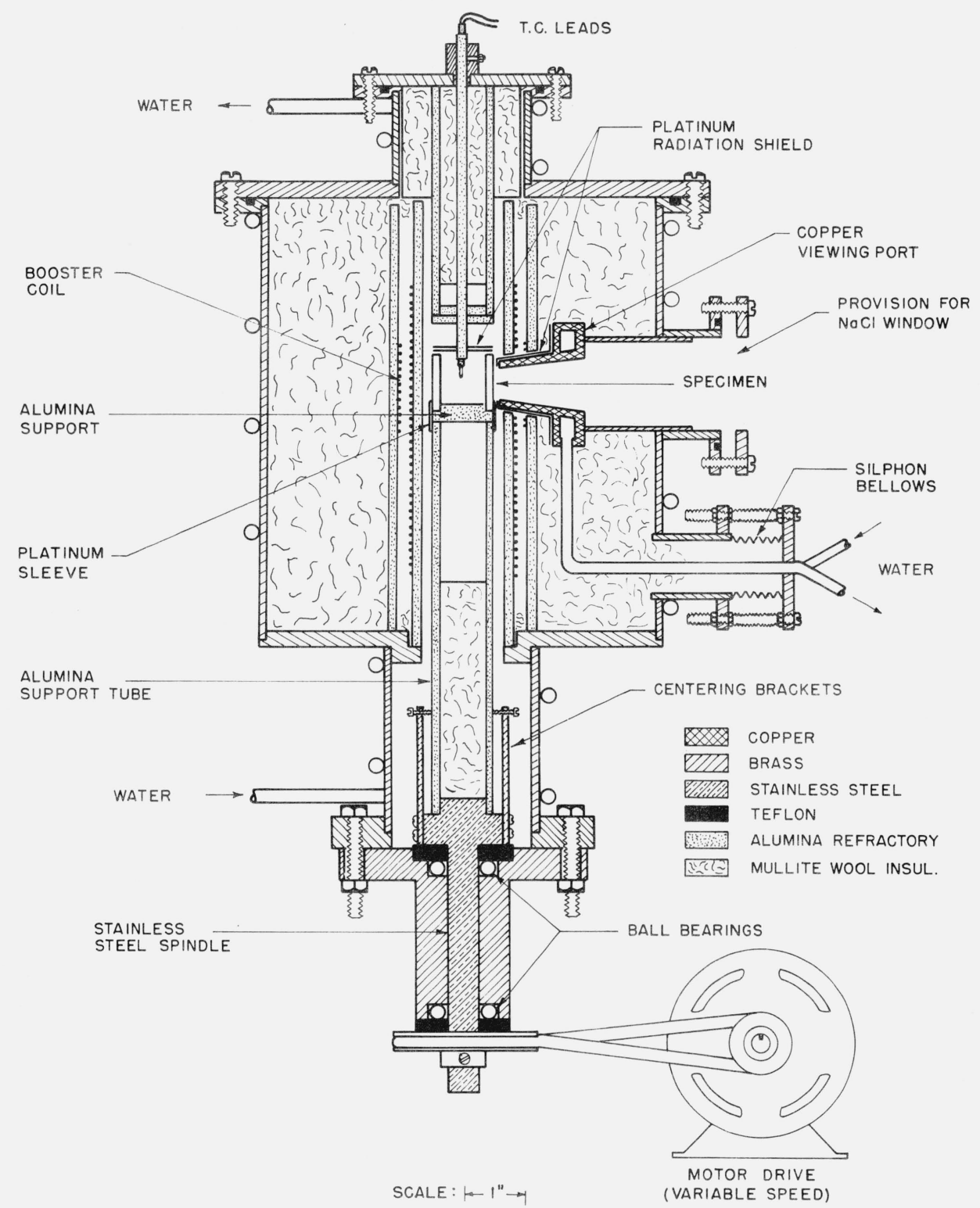

FIGURE 1. Specimen furnace.

Axial temperature gradients in the specimens were reduced to low values by adjusting the power to the booster coil. The gradients were measured by sighting a micro-optical pyrometer on a rotating specimen through the viewing port. With the settings used, no temperature difference from top to bottom was observed for any of the specimens at $1200{ }^{\circ} \mathrm{K}$. At $1400^{\circ} \mathrm{K}$, the top may have been as much as $2{ }^{\circ} \mathrm{K}$ higher than the bottom, while at $1600^{\circ} \mathrm{K}$, the top was as much as $6^{\circ} \mathrm{K}$ higher. The precision to which the pyrometer could be read was about $2{ }^{\circ} \mathrm{K}$. The specimen thermocouple was located in the certer of the specimen cavity and was shielded from furnace radiation as shown in figure 1 .

\subsection{Blackbody Furnaces}

a. Details of Construction

Figure 2 is a schematic of the blackbody furnace. Two of these were required in the measurement system, and both were made to be as nearly identical as possible. The inner cavity of the furnaces was formed of fused alumina bonded with 20 percent by weight of a calcium aluminate cement. This mixture, which sets hydraulically, was mixed with 17.5 percent by weight of water and vibrated into a greased plaster mold. The mold was made by using an alumina core as a pattern; a brass mandrel was 


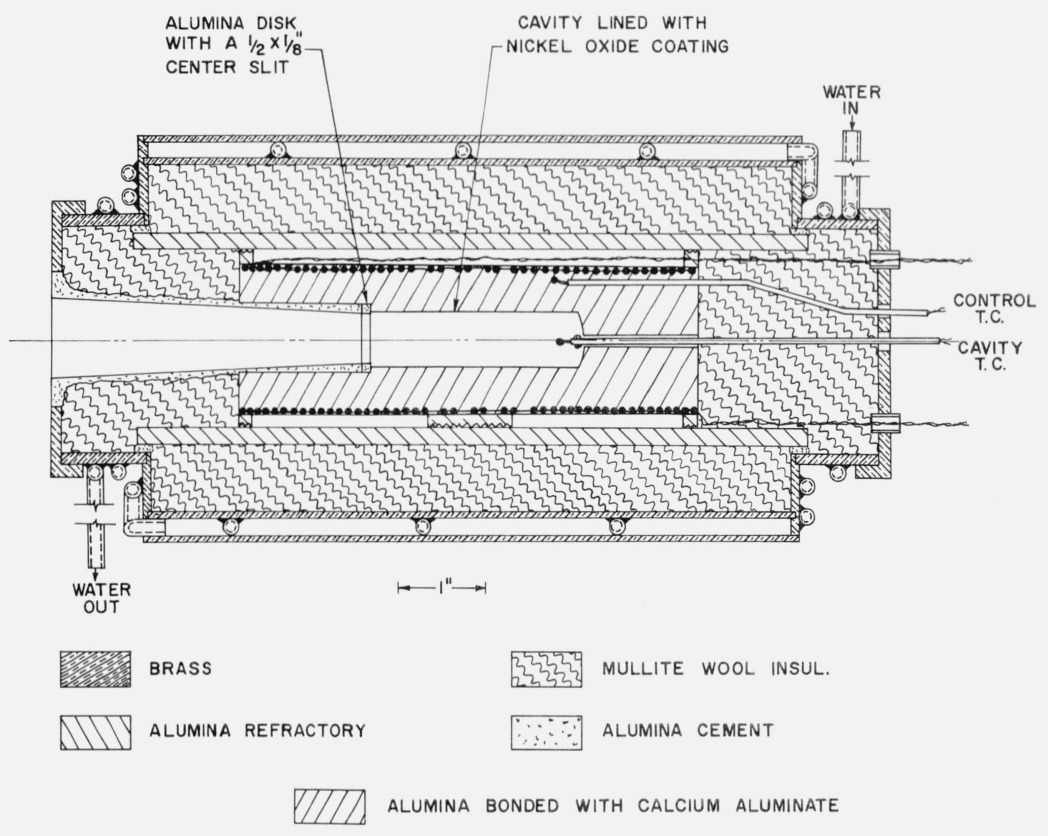

Figure 2. Blackbody furnace.

positioned at the center of the mold to form the outline of the cavity. After allowing $20 \mathrm{hr}$ for curing, the core was removed from the mold, dried in an oven for $24 \mathrm{hr}$, and then heated to $1925^{\circ} \mathrm{K}$ for $1 \mathrm{hr}$. It was later wound with 0.032 -in-diam platinum-40 percent rhodium resistance wire.

An alumina disk with a $1 / 2$-in by $1 / 8$-in center slit was placed over the front end of the cavity to reduce heat losses by radiation. The viewing port was formed with mullite wool, over which was placed a thin layer of alumina cement. The shaping of the port was facilitated by use of a tapered aluminum mandrel that was machined especially for the purpose.

All furnace thermocouples (including the one for the specimen furnace) were made of 0.020 -in-diam $\mathrm{Pt}: \mathrm{Pt}-10$ percent $\mathrm{Rh}$ wire that had been calibrated by the Temperature Physics Laboratory at the $\mathrm{Na}$ tional Bureau of Standards. Two-hole alumina tubing was used to insulate the leads. This tubing was inserted into an alumina sleeve that was cemented into the core so that when the thermocouple was inserted, it would be nearly flush with the side wall of the cavity. With this arrangement, the spectrophotometer did not "see" the thermocouple bead, but rather was "looking" at the back of the cavity, which was largely isothermal. Of course, no important deviation from blackbody conditions would result from the presence of the thermocouple at the center of the cavity if the cavity was isothermal and if there was no separation between the alumina sleeving and the thermocouple tubing. However, a small clearance was present, and this clearance showed up as a tiny dark crescent when looking into the heated cavity. The presence of a dark area of this type was undesirable, in that it would tend to generate low flux readings.

The alumina core material has a low emittance in the wavelength region 1 to $5 \mu$. Inasmuch as the cavity emittance depends, in part, on the emittance of the walls, it was desirable to line the cavity with a coating that would have a high emittance at the short, as well as the long wavelengths. The coating developed for this purpose consisted of black nickel oxide $\left(\mathrm{Ni}_{2} \mathrm{O}_{3}\right)$ bonded with 7.5 percent by weight of Florida kaolin. This coating was prepared as a coating slip and applied at a thickness of about 0.005 in to the inner wall surfaces of the cavity by a dipping operation. The core was then heated to $1850{ }^{\circ} \mathrm{K}$ for $1 \mathrm{hr}$, to bond the coating to the alumina. The spectral emittance of a cylindrical specimen of the core material coated in this way was found to be above 0.875 at all wavelengths from 1 to $15 \mu$ when measured at $1200{ }^{\circ} \mathrm{K}$. Hence, the lowest possible cavity emittance at any wavelength from 1 to $15 \mu$ was 0.990 when computed by an expression derived by Gouffé [11]. This expression assumes that the walls are diffusely reflecting and that the cavity is isothermal. The expression has been shown to predict slightly low values of emittance for cavities with large depth-to-diameter ratios [12].

\section{b. Temperature Gradients in Blackbody Furnaces}

Several furnace designs were tested early in the study in an attempt to minimize temperature differences within the cavity. To test for gradients, a Pt: Pt-10 percent Rh thermocouple made with 0.010 -indiam wire was inserted into the viewing port and moved 
from front to back with the hot junction within $1 / 8$ in of the interior wall. A record was made of the response at each position. In almost all cases, the indicated wall temperature near the center of the cavity was higher than at either end. In some instances, power was shunted from the central region of the furnace windings, while in other tests, varying numbers of turns were omitted from the heater coil. The final configuration was that shown in figure 2. No shunts were used and four loops were omitted in the central region. With this arrangement, temperature probing revealed that the cavity walls near the back were colder than those in the center by the amounts indicated below. ${ }^{4}$

\begin{tabular}{c|c}
\hline \hline Approximate cavity temperature & Temperature difference \\
\hline${ }^{\circ} K$ & \\
1200 & ${ }^{\circ} K$ \\
1400 & 18 \\
1600 & 14 \\
& 8 \\
\hline
\end{tabular}

The presence of these gradients was a potential source of error in the measurements because of (a) uncertainty in determining the temperature to assign to the "blackbody" radiation, and (b) deviations from the Planck distribution of energy caused by the nonisothermal conditions. Naturally, it would be desirable if the spectral distribution of radiated energy, $E(\lambda)$, was proportional to the Planck function, $W(\lambda, T)$; i.e., $E(\lambda)=\epsilon_{\text {cav. }} W(\lambda, T)$. It was not immediately evident, however, that any single temperature could be assigned to the nonisothermal cavity. Temperatures that might be considered are the temperature of a thermocouple placed in the center of the cavity, the temperature of the back wall of the cavity, or the temperature indicated by an optical pyrometer sighted on the mouth of the cavity. This latter temperature was selected, since it represented the temperature of a perfect blackbody whose radiance at $0.65 \mu$ was the same as that of the nonisothermal laboratory furnace. A theoretical analysis is presented in appendix A to show that when a radiance match is achieved at $0.65 \mu$ then the spectral distribution of radiated energy can be approximated by a Planck function over the 1 to 15 $\mu$ range with no more than a 0.5 percent error.

The procedure used for positioning the furnace thermocouple so that its response would agree with the temperature measured with a calibrated optical pyrometer was as follows:

(1) The furnace was first heated to the desired operating temperature and allowed to stabilize.

\footnotetext{
${ }^{4}$ Large uncertainties existed in temperature measurements made near the front of the cavity, because of excessive heat losses by conduction along the thermocouple leads and the protection tubing.
}

(2) A micro-optical pyrometer was then sighted at the front opening of the furnace and the "optical" temperature of the furnace cavity was determined.

(3) The furnace thermocouple was next moved to a position where its response indicated the same temperature as that measured with the optical pyrometer. This position was always within 1 in of the rear wall of the cavity.

(4) Finally, a mark was placed on the thermocouple tubing at the back of the furnace shell so that the positioning of the junction could be duplicated in subsequent determinations at the same test temperature. This positioning was checked periodically to be certain that no changes in the temperature behavior of the furnace had occurred.

The calibration procedure as outlined needed to be applied to only one blackbody furnace. The position of the thermocouple in the second blackbody furnace could then be adjusted by noting the shape of the spectral curve that compared the energy from these two furnaces (100 percent line, see sec. 4). At long wavelengths, small temperature differences between the furnaces lead to negligible differences in energy content of the two beams, but at short wavelengths they had a pronounced effect. Thus, if the 100 percent curve was higher at $1 \mu$ than at, say, $9 \mu$, it indicated that furnace No. 2 was at a higher temperature than the reference blackbody (No. 1). The thermocouple in No. 1 was then moved to a position where it indicated a lower temperature. The automatic control equipment would then lower the temperature of No. 2 until it matched that of No. 1 and a new spectral curve was determined. This procedure was repeated until a flat 100 percent line was obtained. When this condition was achieved, the furnace No. 1 was at the same effective temperature as No. 2 in that it was supplying an equivalent flux to the spectrophotometer.

\subsection{Temperature Control System}

A differential thermocouple control system similar to that described by Harrison et al. [13], was used to maintain temperature differences of less than $1^{\circ} \mathrm{K}$ between blackbody No. 1 and either the specimen furnace or blackbody No. 2. The No. 1 furnace was controlled, in turn, by a separate temperature controller, which maintained its temperature to $\pm 0.5^{\circ} \mathrm{K}$. A double-pole, double-throw switch was used for switching the differential thermocouple controller from blackbody No. 2 to the specimen furnace.

The differential thermocouple controller was actuated by the difference in signal between the thermocouple in blackbody furnace No. 1 and the thermocouple in either blackbody No. 2 or the specimen furnace. This signal was amplified by a d-c amplifier and fed to a center-zero recorder-controller. The output of the recorder-controller, which was proportional to the temperature difference between the two furnaces, was fed to a current-actuating mechanism that provided three types of current control. One type was proportional to the input signal, a second to the first 


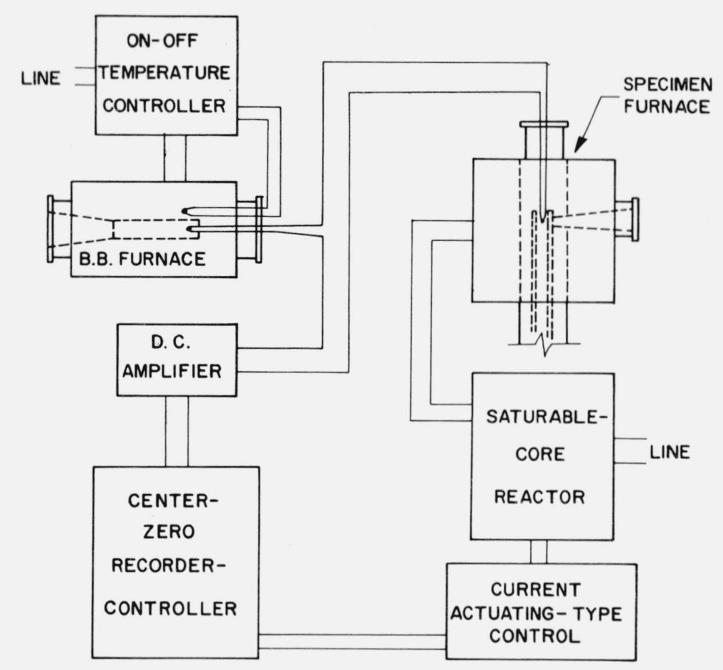

Figure 3. Block diagram of temperature control equipment Controller is actuated by signal from differential thermocounle.

time derivative of the input signal, and a third selected the frequency at which the first correction was repeated. The output from this current actuating device was fed to the coil of a saturable-core reactor, which then varied the power input to either blackbody No. 2 or the specimen furnace, so as to bring the temperature into agreement with the reference blackbody (No. 1).
A block diagram of the temperature control equipment is shown in figure 3 . The system gave almost trouble-free operation at 1200,1400 , and $1600{ }^{\circ} \mathrm{K}$. However, at $1800{ }^{\circ} \mathrm{K}$, it became largely inoperative because of excessive noise in the thermocouple signal. This may have originated from electrical leakage through the alumina core material, whose electrical conductivity becomes appreciable at these very high temperatures. For this reason, no measurements at $1800{ }^{\circ} \mathrm{K}$ were possible, even though all of the furnaces could be operated at this temperature.

\subsection{Spectrophotometer and Transfer Optics}

A double-beam infrared spectrophotometer with a sodium chloride prism was used for obtaining the radiance comparisons. This instrument, which utilizes a chopper operating at $10 \mathrm{~Hz}$, was modified to operate from 1 to $15 \mu$ rather than in the intended 2 to $16-\mu$ range. A second modification consisted of reducing the angle of the attenuator-comb in the reference beam from blackbody No. 1, so that the maximum opening of the comb did not exceed the height of the furnace apertures. This required only a small reduction in the comb angle.

The double-beam optical system of the instrument was used for all measurements. When operating in this mode, the spectrophotometer achieves a null balance through use of the aforementioned mechanically-driven attenuator, or comb, in the reference

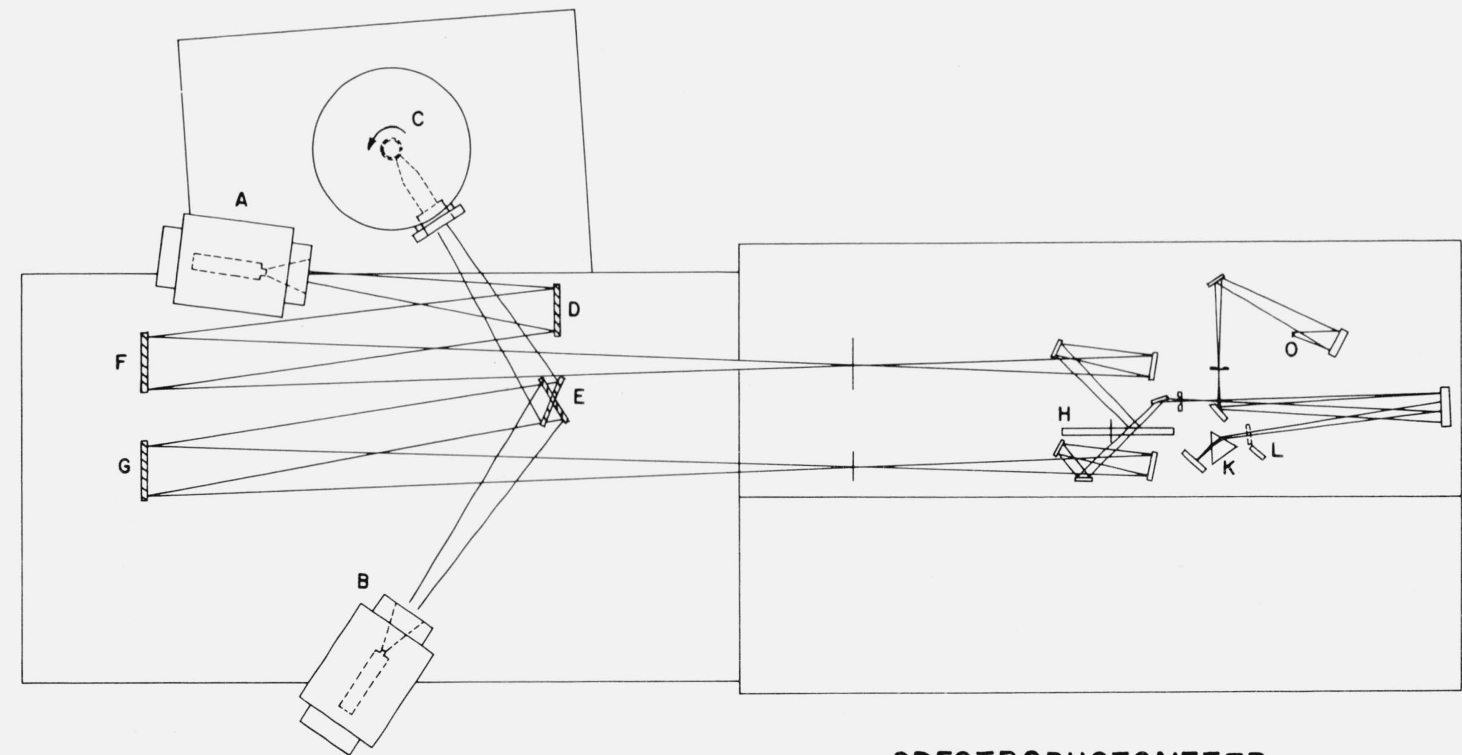

TRANSFER OPTICS

\section{SPECTROPHOTOMETER}

H. $10 \mathrm{c} / \mathrm{s}$ mirror-type chopper

K. $\mathrm{NaCl}$ prism

L. Movable mirror (for total normal measurements)

o. Vacuum-type thermocouple detector

B. Blackbody furnace No. 2

C. Rotating specimen furnace

D. Flat front surface mirror

E. Movable flat mirror

E and G. spherical mirrors, $3^{\prime \prime}$ diam., 18 " focal length

FIGURE 4. Arrangement of equipment showing optical paths of the two beams. 


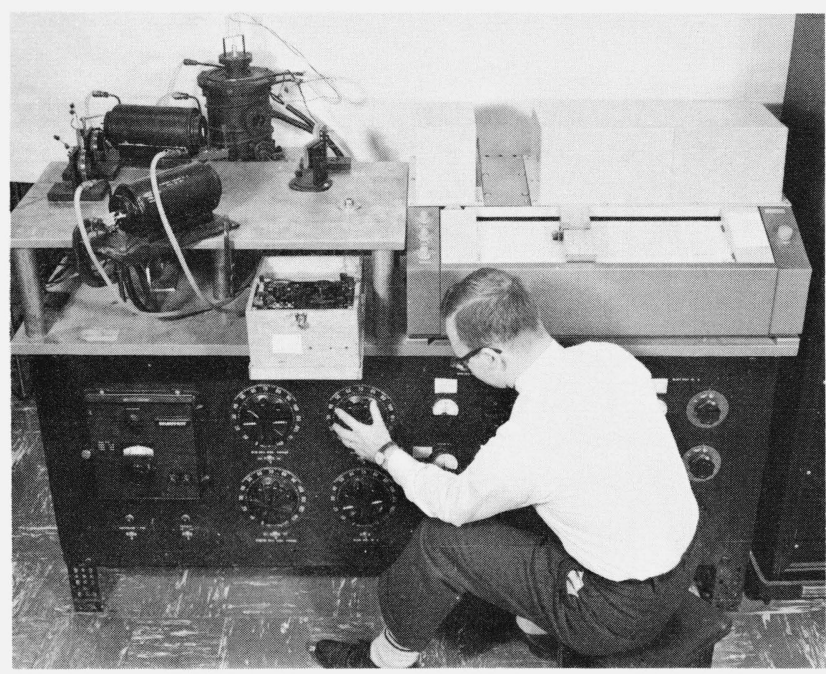

Figure 5. Equipment in operation.

beam. A recorder pen, coupled mechanically to the comb, permits the ratio of the radiances of the two beams to be continuously recorded with respect to wavelength. In all measurements reported herein, the instrument was set to scan the $1-$ to $15-\mu$ range in $16 \mathrm{~min}$.

Prior to using the instrument, the source optics were removed and replaced with the transfer optics shown schematically in figure 4 . The off-axis angle of the two spherical mirrors was approximately $5^{\circ}$.

Figure 5 is a photograph of the equipment in operation.

\subsection{Calibration for Linearity of Response}

The response of the modified instrument to known attenuations of flux in the specimen beam was determined through use of sectored-disk attenuators. To conduct this test both blackbodies were first adjusted to some temperature in the range 1200 to $1600{ }^{\circ} \mathrm{K}$. A sectored-disk attenuator was then inserted into the specimen beam and rotated at high speed (greater than $500 \mathrm{rpm})$. Six disks were used with measured transmission factors of $75.1,50.1,25.3,12.7$, and 5.1 percent, respectively. The resulting spectral curves, which were found to be reproducible to within the precision of measurement, showed that the instrument response was always lower than the actual beam attenuation. This lowering was the same at all wavelengths. Wide variations in disk speed above $500 \mathrm{rpm}$ had no effect on the instrument response, which showed that resonance coupling between the chopper and attenuator was not affecting the results.

Since no method could be devised to restore linearity to the modified instrument, a correction curve (fig. 6) was prepared. This curve was then used to correct the spectral emittances that were obtained by the procedure outlined in section 4 . The dashed line in figure 6 shows the type of behavior expected from an instrument with a completely linear response.

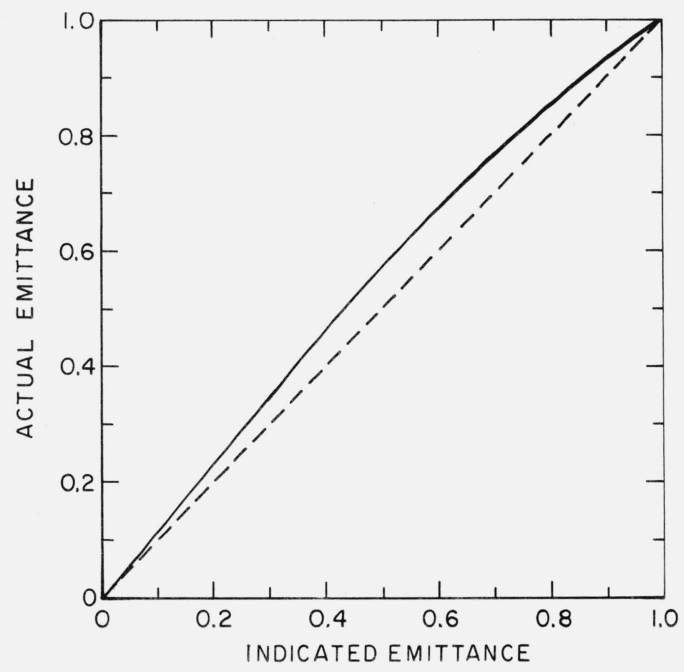

FIGURE 6. Calibration curve (solid curve) for correcting for lack of instrument linearity.

Dashed line shows type of behavior desired of an instrument (linear response).

\section{Measurement Procedure}

In making a determination, a specimen was first placed on the top of the refractory pedestal, carefully centered, and then fixed in position with high-temperature alumina cement. This centering and mounting operation was performed outside the furnace with the aid of a specially prepared jig. After the mounting had been completed, the pedestal was inserted into the furnace from the bottom and carefully positioned radially by a screw adjustment of the bottom flange, so that the specimen rotated at an average distance of 0.010 in from the inner face of the viewing port. The separation distance was measured optically by a telescope with a calibrated reticle. The telescope was sighted through the top of the furnace tube while the furnace was at approximately $1400{ }^{\circ} \mathrm{K}$. Specimen wobble did not exceed \pm 0.005 in.

After positioning of the specimen was completed, the top insulation was replaced, the motor drive was started, and the specimen was brought to a rotational speed of $100 \mathrm{rpm}$. The controller on blackbody No. 1 was then adjusted to $1600{ }^{\circ} \mathrm{K}$ and the differential thermocouple controller actuated to bring blackbody No. 2 to the same temperature. As soon as the temperatures had equilibrated, the flux from blackbody No. 2 was compared to that from blackbody No. 1 by scanning from 1 to $15 \mu$. The resulting curve, a representative section of which is shown in figure 7 , was termed the 100 percent line. Next, the beam from blackbody No. 2 was blocked, and a second curve was obtained on the same chart paper. This is the zero line shown in figure 7 .

After the zero line had been obtained; the automatic control was switched to the specimen furnace, the movable mirror (see fig. 4) was shifted to the specimen 


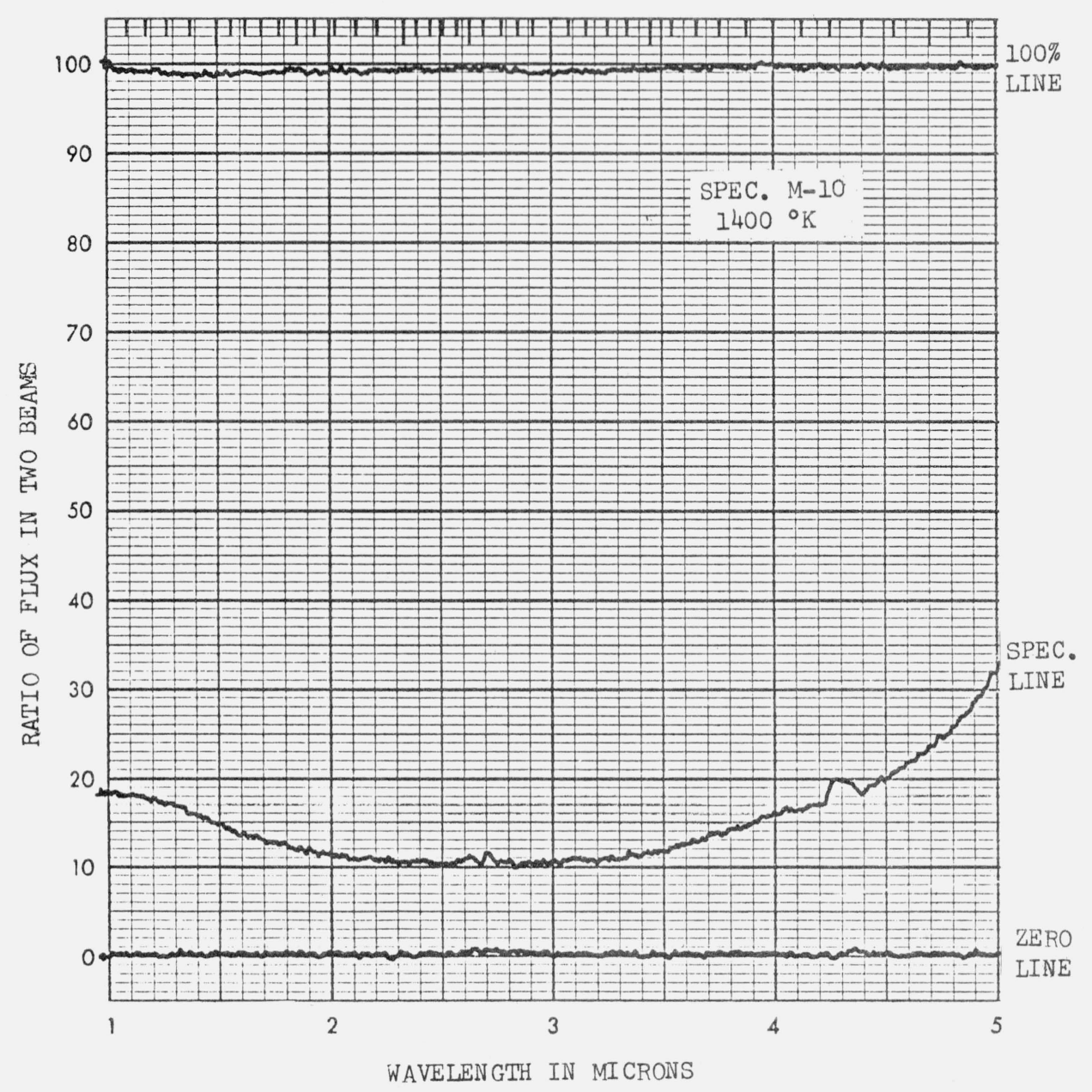

FIGURE 7. Section of recorder chart showing segments of a "100 percent Line," "Specimen Line," and "Zero Line."

position, and after an equilibrium condition had been attained a specimen curve was plotted, again on the same chart paper.

Curves such as those shown, in part, in figure 7 represent raw data for one determination at one temperature. To transform these data to an actual or true spectral emittance curve for the specimen, two operations were performed:

(1) The height of the specimen curve at preselected wavelengths was obtained as a ratio of the respective heights of the zero and 100 percent lines. Stated mathematically, if $Z_{\lambda}$ is the height of the zero line, $S_{\lambda}$ the height of the specimen curve, and $H_{\lambda}$ the height of the 100 percent line, then $\epsilon_{\lambda i}$, the uncorrected or "indicated" emittance, is

$$
\boldsymbol{\epsilon}_{\lambda i}=\frac{S_{\lambda}-Z_{\lambda}}{H_{\lambda}-Z_{\lambda}}
$$

Values for $\epsilon_{\lambda i}$ were, in most cases, obtained at intervals of $0.5 \mu$.

(2) The values for $\epsilon_{\lambda i}$ were next converted to true or actual emittances, $\epsilon_{\lambda}$ through use of the calibration curve shown in figure 6 . These values were then plotted against wavelength to obtain the curves shown in later sections of the report.

In all data reported herein, measurements on each specimen were made first at $1600^{\circ} \mathrm{K}$, next at $1400^{\circ} \mathrm{K}$, and finally at $1200^{\circ} \mathrm{K}$; all three measurements being made during a single working day. Three specimens of each type were measured, and two completely independent determinations were made on each specimen. These duplicate determinations on the same specimen were always made on different working days, and in each case, the specimen had been removed from the furnace between the first and second series of measurements. 


\section{Discussion of Errors}

\subsection{Transfer Optics}

An important consideration in the design of any double beam system is the requirement of complete optical equivalence of the two beams. Failure to meet this requirement would cause inflections in the spectral curves due to differential absorption by the atmosphere or by the mirrors in the system. In the present study the use of the two blackbodies to obtain a 100 percent line provided a convenient means to check for these effects.

\section{a. Atmospheric Absorption}

In most double-beam infrared spectrophotometers, no irregularities are observed when scanning through the absorption bands for carbon dioxide and water vapor, since the flux attenuation is the same for both beams. However, the flux available for measurement drops off drastically at the major absorption bands. In the present measurements, no appreciable inflection in the curve was observed at the strong water absorption band at $2.7 \mu$, since at this wavelength there was apparently sufficient energy in the beams to allow the instrument to compensate for the sudden change in flux. At longer wavelengths, however, there was considerably less energy in the beams, and whenever the instrument scanned through the strong absorption band for carbon dioxide at $4.2 \mu$, a small discontinuity in the curve was observed. However, since this represented a deficiency of the instrument rather than an abrupt change in specimen emittance, a smooth curve was drawn through the minor inflection at $4.2 \mu$. Any error resulting from this procedure would be extremely small and would apply to this one wavelength only.

\section{b. Preferential Mirror Absorption}

A thin protective layer of silicon oxide was present on the aluminum front surface mirrors procured for the transfer optics in the present equipment. Coating layers of this type normally consist of mixtures of such compounds as $\mathrm{SiO}, \mathrm{SiO}_{2}$, and $\mathrm{Si}_{2} \mathrm{O}_{3}$, all of which have absorption bands in the 8- to $10-\mu$ region [14].

The presence of the silicon oxide layer on the mirrors would have no appreciable effect on the measurements if (a) the same number of mirrors were in both optical paths, (b) the coating thicknesses were the same on all mirrors, and (c) the respective beams struck the mirrors at the same angle for the determination of both the 100 percent and specimen curves. Unfortunately, this last requirement was not fulfilled since the beam from blackbody No. 1 strikes the plane mirror D (see fig. 4) at an angle of incidence of $9^{\circ}$ while the beams from blackbody No. 2 and from the specimen strike the mirror $\mathrm{E}$ at angles of $19^{\circ}$ and $32^{\circ}$, respectively. These differences in angle caused different attenuations in the respective beams at the wavelengths where the silicon oxide layer is highly absorbing but not at other wavelengths.
Because of this differential absorption effect, all 100 percent lines and specimen curves showed a small dip in the 8 to $10 \mu$ region. The emittance curves included in this report have been smoothed out over the 8- to $10-\mu$ region. Since this smoothing operation is equivalent to taking no data points in this region, the emittances indicated on the curves at both $8.5 \mu$ and at $9 \mu$ have greater uncertainty than those at other wavelengths.

\subsection{Extraneous Transmitted and Reflected Radiation}

In the paragraphs which follow, an attempt is made to place an upper limit on the magnitude of the errors that can arise due to extraneous radiation, i.e., energy which contributes to the radiance of the specimen beam but does not originate at the specimen.

\section{a. Nonopacity of Specimen Wall}

As mentioned in the introduction, many polycrystalline ceramic oxide specimens are partially transparent to radiation in the visible and the near infrared. Hence, when measuring emittance, if the specimen wall is not sufficiently thick to be opaque, energy from within the specimen cavity will pass through the specimen wall and enter the specimen beam. Since with the present measurement method this energy will approximate blackbody radiation, high emittance readings will result unless the wall thickness is sufficient to provide the required opacity.

Earlier work had suggested that a wall thickness of $3 / 16$ in would be adequate for the particular materials selected for study [9]. However, to be certain that the $3 / 16$-in thickness was sufficient in all cases, specimens with $5 / 16$-in walls were also measured. If the emittances were the same for both, then it would be almost positive evidence that the transmittance through the $3 / 16$-in wall was too small to cause an error.

Tests of this type were made for each material. The agreement between specimens with $3 / 16$-in and 5/16-in-thick walls was, in each case, within the precision of measurement; hence, it was concluded that there was no measurable error from wall transmission when the specimens with $3 / 16$-in-thick walls were used.

\section{b. Furnace Radiation Reflected Into Specimen Beam}

The purpose of the water-cooled viewing port in the specimen furnace is to reduce extraneous flux, both emitted and reflected, from entering the specimen beam. Emitted flux is reduced to an insignificant level by water-cooling the walls of the port. To diminish reflected flux, however, the specimen must rotate in close proximity to the inner face of the port; otherwise, as illustrated in figure 8 , flux from the furnace walls will strike the face of the specimen and be diffusely reflected into the specimen beam thereby giving high values of emittance.

It was recognized early in the investigation that large errors could result if sizeable separations were permitted between specimen and viewing port [15]. A theoretical computation of errors caused by various 


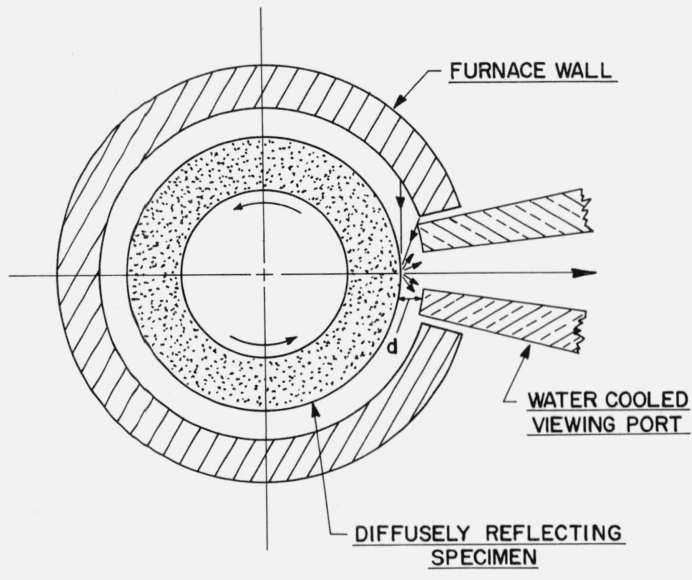

FIGURE 8. Illustration of how flux from furnace walls may be diffusely reflected into specimen beam.

separations was not feasible because of uncertainties in (a) the local furnace wall temperatures, and (b) the optical properties of the specimens. Thus an attempt was made to arrive at their magnitude experimentally.

The experiment consisted of determining the indicated emittance of various specimens at carefully measured distances of separation. To accomplish this, a screw adjustment was incorporated on the brass flange at the bottom of the specimen furnace. By turning this screw, the rotating pedestal could be moved in known increments toward or away from the viewing port. A microscope with a calibrated reticle was used to measure the distance of separation to \pm 0.001 in.

To evaluate the effect of separation distance, the specimen was first brought to a temperature near $1400{ }^{\circ} \mathrm{K}$ with the microscope mounted above the top furnace opening. Next, the specimen was moved forward so that the average separation between the surface of the specimen and the viewing port was 0.010 in. In all of these particular tests, specimen wobble was less than \pm 0.002 in. After completing the distance measurement, the microscope was moved out of position, the top cover reinserted, the furnace temperature allowed to stablize, and a spectral curve determined. Then, by adjusting the calibrated screw, the specimen was moved back from the viewing port in known increments. After each step, the emittance was determined at certain selected wavelengths. Finally, when the limit of travel of the adjusting screw had been reached, the microscope was again used to verify the final separation distance.

The first measurements of this kind were made with a polished platinum specimen. As might be predicted, no change occurred with separation distance, since all wall radiation that struck the viewed area of the specimen was specularly reflected away from the viewing port and did not enter the specimen beam.

When the same platinum specimen was grit-blasted, however, its surface became a partially diffuse reflector and the measured emittance was no longer insensitive to separation distance. This is illustrated by the solid curves in figure 9. At each of the four wavelengths, the rate of change of measured emittance with distance decreased as the distance approached zero. In fact, the shape of the curves suggests that if all measurements had been made with a separation of $0.01 \mathrm{in}$, which is as small as was practical with the present system, the measured values would be high by no more than about 0.005 in emittance.

Platinum, like other metals, is substantially opaque to radiation in the $1-$ to $15 \mu$ region. This means that the reflection occurs at or very near the surface. In the case of polycrystalline ceramics, however, reflection occurs largely by internal scattering. Flux striking the surface can penetrate to appreciable distances and then reemerge, after multiple internal reflections, at a point on the surface that may be appreciably separated from the point where it entered. This particular reflection behavior is believed to be responsible for the type of results obtained with the ceramic oxide specimens. The data for an alumina specimen plotted as dashed lines in figure 9 are typical. It will be noted that the rate of change of measured emittance with distance is largely unchanged as the specimen approaches the viewing port. This behavior at least implies that even if a zero separation was possible, radiation from the furnace walls would still be penetrating the surface at some distance from the viewing port and then reemerging at the port to enter the specimen beam. However, when emittances as low as 0.04 (Alumina, $2 \mu, 1200^{\circ} \mathrm{K}$ ) were measured, it seems unlikely that they could be high by more than 0.02 , notwithstanding any compensating errors. Various attempts were made either to eliminate or precisely evaluate the magnitude of this error, but none were successful.

\subsection{Errors From Temperature Uncertainties}

The comparison method of measuring emittance requires that the specimen and blackbody furnaces all be maintained at the same temperature. If this condition is not fulfilled, an error is introduced that is dependent upon (a) the magnitude of the temperature difference, (b) the wavelength, and (c) the test temperature. Since the thermocouples were prepared from wires taken from the same spools and were checked periodically, and since the controller maintained the thermocouples at the same temperature to within better than $1.0^{\circ} \mathrm{K}$, no sizeable error from temperature difference would be expected unless the thermocouples failed to indicate the "true" temperatures of the specimen and the reference blackbody.

With a specimen speed of $100 \mathrm{rpm}$, the analysis described in section 2 indicated that since radial gradients are small, the specimen thermocouple should be in close agreement with the specimen temperature and, hence, no important error should result from this source.

As mentioned in section 3.2.a, temperature gradients existed in the blackbody furnaces. However, 


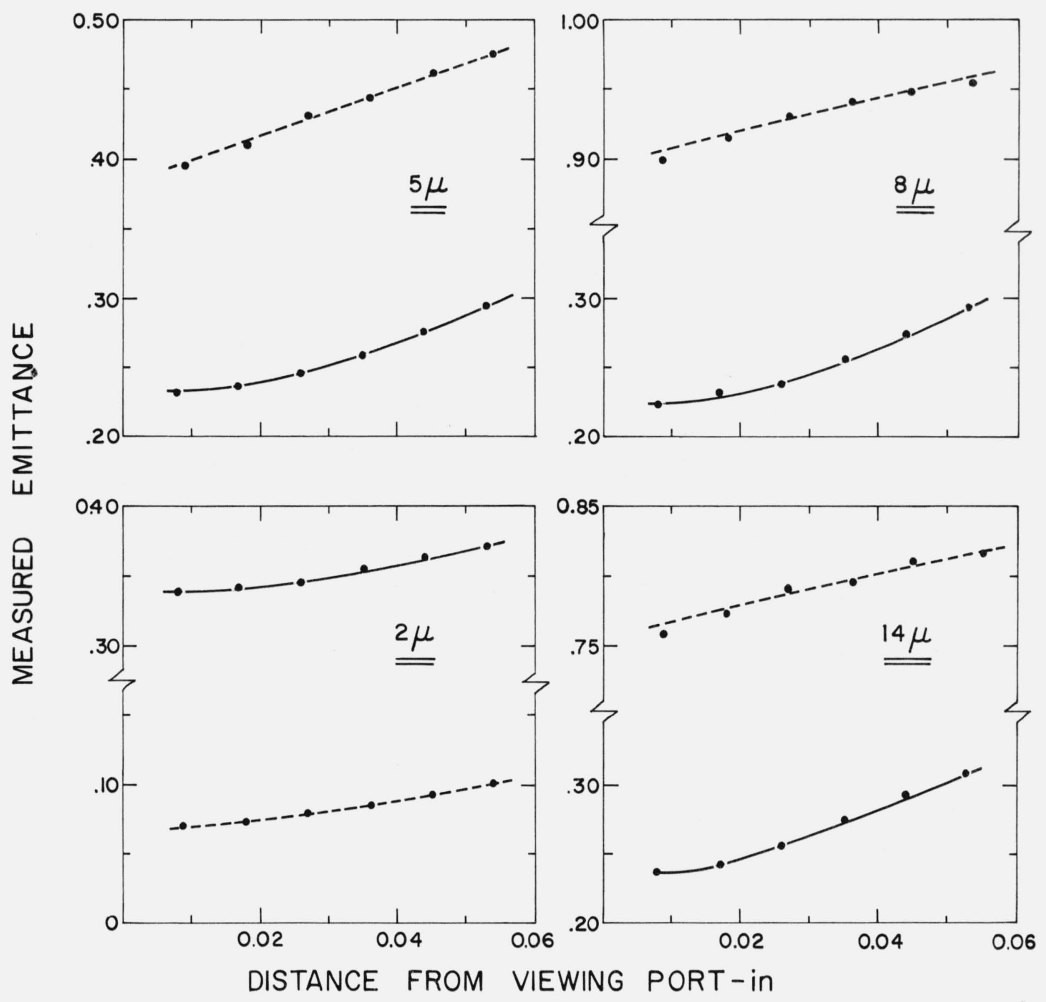

FIGURE 9. Effect of distance of specimen from viewing port on measured emittance of grit-blasted platinum specimen (solid lines) and a polycrystalline alumina specimen (dashed lines).

as shown in appendix $\mathrm{A}$, when the thermocouple is located so that its response agrees with an optical pyrometer sighted on the cavity, the distribution of radiated flux at $1 \mu$ differs from a Planck distribution by less than $1 / 2$ percent at $1200{ }^{\circ} \mathrm{K}$. The size of this error decreases with both increasing temperature and wavelength. If the true emittance of the specimen was 0.10 , then an error of the magnitude discussed above would change the measured emittance by only 0.0005 , a completely negligible quantity.

From the foregoing discussion it follows that any uncertainty in temperature measurements will depend primarily upon the accuracy and precision of the optical pyrometer used for positioning the thermocouple. Since the instrument had been carefully calibrated and periodically checked by the National Bureau of Standards Temperature Physics Section, it is unlikely that the combined uncertainty due to inaccuracy of the pyrometer and imprecision introduced by the operator would exceed $\pm 5^{\circ} \mathrm{K}$.

At wavelength $\lambda$, temperature $T$, and uncertainty $d T$, a sample whose true emittance was $\epsilon_{t}$ would appear to have an emittance $\epsilon_{m}$ given by

$$
\epsilon_{m}=\frac{\epsilon_{t} W(\lambda, T)}{W(\lambda, T+d T)}=\frac{\epsilon_{t} W(\lambda, T)}{W(\lambda, T)+d W}
$$

where $W(\lambda, T)$ is the Planck function. Dividing both numerator and denominator by $W(\lambda, T)$ one obtains

$$
\epsilon_{m}=\epsilon_{t} \frac{1}{1+\frac{d W}{W}}=\epsilon_{t} \frac{1}{1+F \frac{d T}{T}}
$$

where the factor $F=F(\lambda T)$ relating $\frac{d W}{W}$ to $\frac{d T}{T}$ is a tabulated function [16].

For the purpose of estimating errors it is more useful to have the true emittance in terms of a measured value. Thus eq (3) is written

$$
\epsilon_{t}=\epsilon_{m}\left(1+F \frac{d T}{T}\right)
$$

If the uncertainty in temperature is $\pm 5{ }^{\circ} \mathrm{K}$ at $T=1200{ }^{\circ} \mathrm{K}$ and $\lambda=2 \mu$, then $F=6.2$ and

$$
\epsilon_{t}=\epsilon_{m} \pm 0.026 \epsilon_{m} \text {. }
$$

Thus, a sample whose measured emittance was 0.050 would be in error by no more than $\epsilon_{t}-\epsilon_{m}= \pm 0.026$ $\times 0.050= \pm 0.0013$. Similarly, if the measured emittance was 0.30 at $2 \mu$ and $1200{ }^{\circ} \mathrm{K}$, the error would be $\epsilon_{t}-\epsilon_{m}= \pm 0.0078$. The function $F$ is a monotonically decreasing function of the product $\lambda T$; emittance, on 
the other hand, generally increases. The net result is that errors of this type are not greatly influenced by changes in either wavelength or temperature.

The effect of a temperature gradient along the axis of the specimen may be treated in much the same way. As pointed out in section 3.1 this gradient amounts to little more than $5{ }^{\circ} \mathrm{K}$ so that some sort of "average" temperature $T^{\prime}$ may be assigned to the specimen. When this is done, it then becomes possible to approximate the flux from the specimen, $N(\lambda)$, by $\epsilon_{t} W\left(\lambda, T^{\prime}\right)$ with very little error. Only if the thermocouple bead was located at the extreme top or bottom of the specimen cavity, would its temperature differ from $T^{\prime}$ by even $3{ }^{\circ} \mathrm{K}$. Since the bead is carefully positioned in the center of the viewed area, it is reasonable to assume, on the basis of the previous discussion, that any errors from temperature differences which may exist along the axis of the specimen are negligible.

\subsection{Random Error of Measurement}

When expressed in terms of emittance, the pooled estimate, $\bar{S}_{w}$, of the standard deviation due to random error of measurement at $\lambda=2 \mu$ was 0.00427 . $\left(\bar{S}_{w}\right.$ is the root mean square value for the $S_{w}$ 's tabulated in table 3). This estimate is based on two completely independent measurements at each of three temperatures on three polycrystalline ceramic oxide specimens of three different materials. ${ }^{5}$ In effect, this standard deviation is an index to the reproducibility of the measurement, and takes into consideration such factors as the ability to mount the specimen on its pedestal with a minimum amount of wobble, the ability to mount each specimen at the same distance from the viewing port, and the ability to return the blackbody thermocouples to the proper position each time the temperature is changed. It also considers the reproducibility of the spectrophotometer, the precision with which the data are read from the charts and corrected for linearity, the day-to-day variations in moisture content of the air and numerous other variables which could affect the reproducibility of the measurements; and finally, its value is influenced by the stability of the specimens, i.e., their ability to resist changes caused by the high temperatures (see sec. 6.2c).

More important, however, is the fact that pooled estimates of the standard deviation due to measurement error, like the one above, may be used to establish a confidence interval for the true averages corresponding to the measured emittances given in table 2 . Thus, using the standard statistical formulas, one may conclude with 95 percent confidence that the values listed in this table at $2 \mu$ are within

$$
\Delta=t \cdot \frac{\bar{S}_{w}}{\sqrt{n p}}=2.052 \frac{0.00427}{\sqrt{6}}=0.00358 \approx 0.004
$$

of the true average values (for these three specimens)

${ }^{5}$ The values of $S_{w}$ for zirconia are abnormally high because of the extreme structural instability of this material (see sec. 6.2c). For this reason the zirconia data were omitted from this particular analysis. that would be obtained if an infinite number of measurements were made. In the foregoing expression, $\bar{S}_{w}$ is the pooled estimate of the standard deviation due to random measurement errors, and the value of $t_{0.975}$ was obtained from reference [17] for the case of $9 \times 3=27$ deg of freedom.

\subsection{Estimated Accuracy}

An estimate of the accuracy of measurements made with the rotating-cylinder equipment on nonmetals can be obtained by considering both types of error; i.e., those that cause a bias and those that cause random errors. Let us now assume one of the worst conditions from the accuracy standpoint; i.e., data at $2 \mu$ taken at $1200{ }^{\circ} \mathrm{K}$. Error from extraneous radiation would certainly not exceed +0.02 in emittance. Temperature uncertainties would contribute \pm 0.008 as a maximum while random error of measurement will be on the order of \pm 0.004 (see sec. 5.4). Thus, the true values of emittance at $2 \mu$ and $1200^{\circ} \mathrm{K}$ for the particular specimens measured might be as much as 0.032 lower or 0.012 higher than those listed in table 2 .

The uncertainty in the listed values could, of course, be decreased to \pm 0.012 if the data were corrected for the extraneous radiation that entered the specimen beam. However, as mentioned earlier, the uncertainties as to the exact magnitude of this error were too great to justify this procedure.

\section{Measurements on Polycrystalline Oxide Specimens}

\subsection{Description of Specimens}

The ceramic oxide specimens were obtained commercially. They consisted of hollow cylinders $11 / 16$-in high and $1 \frac{1}{32}$-in o.d. with a wall thickness of $3 / 16$-in, although wall thickness of $5 / 16$-in were also furnished. All specimens were cylindrical to \pm 0.002 in. The outer surfaces were smooth but not polished.

The sintering treatment for all specimens was $27 \mathrm{hr}$ at $1865^{\circ} \mathrm{K}$. Chemical analyses of the raw materials, as provided by the manufacturer, are shown in table 1 .

The measured porosity of the alumina specimens was about 30 percent; of the thoria 13 percent; of the magnesia 30 percent, and of the zirconia 20 percent. All are given as percentage by volume. Grain sizes were not measured.

No attempts were made to characterize the surface finish of the specimens since it was found that roughening the initially smooth surface of an alumina specimen by grit blasting had no measurable effect on emittance in the 1 to $15 \mu$ range. This observation is in agreement with the recent results of Gannon and Linder [18] as well as those reported by Cox [19]. Also, it agrees with the predictions made recently by Richmond as a result of a theoretical analysis of the possible effects of surface roughness on the thermal radiation properties of nonmetals [20]. 
TABLE 1. Vendor's chemical analysis of specimen materials in percentage by weight

\begin{tabular}{|c|c|c|c|c|}
\hline & Alumina ${ }^{a}$ & Thoria ${ }^{b}$ & Magnesia & Zirconia \\
\hline $\begin{array}{l}\mathrm{Al}_{2} \mathrm{O}_{3} \ldots \ldots \ldots \\
\mathrm{ZrO}_{2}+\mathrm{HfO}_{2} \ldots\end{array}$ & 99. + & & 0.1 & $\begin{array}{r}0.15 \\
94.2\end{array}$ \\
\hline $\begin{array}{l}\mathrm{ThO}_{2} \ldots \ldots \\
\mathrm{SiO}_{2} \ldots \ldots\end{array}$ & 0.10 & $99 .+$ & 04 & \\
\hline 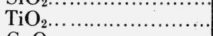 & 0.10 & & 0.4 & $\begin{array}{l}0.00 \\
0.30\end{array}$ \\
\hline $\begin{array}{l}\mathrm{CaO} \ldots \\
\mathrm{MgO} . .\end{array}$ & 0.07 & $\begin{array}{l}\text { trace } \\
0.02\end{array}$ & 0.1 & $\begin{array}{l}4.50 \\
0.07\end{array}$ \\
\hline $\mathrm{Fe}_{2} \mathrm{O}_{3} \ldots \ldots$ & 0.40 & & 0.1 & 0.10 \\
\hline
\end{tabular}

a Also, 0.02 percent $\mathrm{Na}_{2} \mathrm{O}$.

b Also, trace amounts of the oxides of phosphorus, iron, and the rare earths as well as a minor amount of alkali oxides which was expressed in the analysis as 0.10 percent of combined $\mathrm{Na}, \mathrm{K}$, and $\mathrm{Li}$.

\subsection{Results and Discussion}

\section{a. Spectral Emittance Data}

Results of measurements on the four oxide materials are given in table 2 and in figures $10,11,12$, and 13. In each case the values listed or plotted are the averages of six determinations, two each on three specimens, taken at $0.5 \mu$ intervals over the 1 to $15 \mu$ range. The small dip in the magnesia curve (fig. 12) at $6.4 \mu$ was observed for all specimens at all three temperatures.

\section{b. Statistical Scatter of Data}

The statistical scatter of the data at 1200,1400 , and $1600{ }^{\circ} \mathrm{K}$ is listed in tables 3 and 4 . The sample esti- mate of the standard deviation due to error of measurement, $S_{w}$ (i.e., due to differences within specimens), was computed from the expression given below [21].

$$
S_{w}=\sqrt{\frac{\sum_{1}^{n}\left(x-\bar{x}_{1}\right)^{2}+\sum_{1}^{n}\left(x-\bar{x}_{2}\right)^{2} \ldots+\sum_{1}^{n}\left(x-\bar{x}_{p}\right)^{2}}{(n-1) p}}
$$

where $x$ is an individual measurement, $\bar{x}_{1}$ is the average of $n$ measurements on one specimen, and $p$ is the number of specimens. For data in this report, $n=2$, $p=3$, and $S_{w}$ corresponds to $(n-1) p=3$ deg of freedom.

A sample estimate of the overall standard deviation due to differences in specimens and random errors of measurement $S_{\bar{x}}$ was also computed. The expression used for this computation was

$$
S_{\bar{x}}=\sqrt{\frac{\sum_{1}^{p} \overline{(x-\overline{\bar{x}})^{2}}}{p-1}}
$$

where $\overline{\bar{x}}$ is the overall average of the $n \times p$ measurements, $n$ each on $p$ specimens. $S_{\bar{x}}$ corresponds to $p-1=2 \mathrm{deg}$ of freedom. One could, if it were desired, use the values of $S_{\bar{x}}$ given in table 4 to set up a confidence interval for the true mean of the entire population of specimens similar to those described

\begin{tabular}{|c|c|c|c|c|c|c|c|c|c|c|c|c|}
\hline \multirow{3}{*}{$\begin{array}{l}\text { Wave- } \\
\text { length }\end{array}$} & \multicolumn{12}{|c|}{ Emittance $^{\text {a }}$} \\
\hline & \multicolumn{3}{|c|}{ Alumina } & \multicolumn{3}{|c|}{ Thoria } & \multicolumn{3}{|c|}{ Magnesia } & \multicolumn{3}{|c|}{ Zirconia } \\
\hline & 1200 & 1400 & 1600 & 1200 & 1400 & 1600 & 1200 & 1400 & 1600 & 1200 & 1400 & 1600 \\
\hline $\begin{array}{l}\mu \\
1.0\end{array}$ & 0.060 & 0.073 & 0.097 & 0.259 & 0.347 & 0.418 & 0.182 & 0.201 & 0.227 & 0.163 & 0.207 & 0.297 \\
\hline 1.5 & .046 & .063 & .088 & .235 & .330 & .407 & .131 & .162 & .196 & .148 & .192 & .269 \\
\hline 2.0 & .042 & .061 & .085 & .223 & .319 & .399 & .095 & .124 & .151 & .129 & .172 & .247 \\
\hline 2.5 & .045 & .065 & .089 & .216 & .314 & .398 & .088 & .114 & .141 & .131 & .172 & .243 \\
\hline 3.0 & .058 & .075 & .097 & .214 & .311 & .395 & .088 & .114 & .144 & .137 & .177 & .244 \\
\hline 3.5 & .080 & .106 & .125 & .215 & .314 & .396 & .102 & .133 & .160 & .150 & .188 & .250 \\
\hline 4.0 & .141 & .169 & .177 & .223 & .318 & .400 & .149 & .181 & .205 & .187 & .222 & .262 \\
\hline 4.5 & .248 & .287 & .316 & .238 & .330 & .406 & .191 & .229 & .260 & .266 & .308 & .356 \\
\hline 5.0 & .389 & .431 & .459 & .297 & .366 & .429 & .336 & .368 & .388 & .416 & .448 & .482 \\
\hline 5.5 & .530 & .572 & .595 & .359 & .416 & .471 & .502 & .526 & .546 & .537 & .572 & .585 \\
\hline 6.0 & .653 & .696 & .715 & .416 & .473 & .521 & .593 & .623 & .640 & .626 & .654 & .676 \\
\hline 6.5 & .789 & .821 & .832 & .491 & .544 & .586 & .613 & .659 & .687 & .713 & .744 & .760 \\
\hline 7.0 & .892 & .910 & .912 & .575 & .624 & .662 & .692 & .732 & .755 & .791 & .818 & .826 \\
\hline 7.5 & .945 & .956 & .955 & .667 & .714 & .747 & .777 & .809 & .827 & .855 & .872 & .876 \\
\hline 8.0 & .968 & .975 & .973 & .757 & .793 & .817 & .840 & .855 & .878 & .892 & .902 & .906 \\
\hline $8.5^{\mathrm{b}}$ & .939 & .947 & .944 & .802 & .825 & .838 & .852 & .871 & .879 & .876 & .885 & .882 \\
\hline $9.0^{\mathrm{b}}$ & .965 & .973 & .967 & .878 & .893 & .894 & .911 & .926 & .929 & .913 & .920 & .919 \\
\hline 9.5 & .978 & .985 & .981 & .918 & .929 & .928 & .947 & .958 & .959 & .935 & .942 & .940 \\
\hline 10.0 & .984 & .989 & .986 & .934 & .942 & .939. & .966 & .972 & .970 & .949 & .954 & .952 \\
\hline 10.5 & .982 & .987 & .986 & .939 & .946 & .946 & .976 & .978 & .978 & .957 & .960 & .957 \\
\hline 11.0 & .958 & .972 & .971 & .941 & .949 & .949 & .975 & .981 & .977 & .961 & .965 & .962 \\
\hline 11.5 & .885 & .909 & .921 & .947 & .954 & .953 & .976 & .981 & .977 & .964 & .968 & .965 \\
\hline 12.0 & .836 & .860 & .873 & .954 & .960 & .957 & .983 & .982 & .980 & .970 & .973 & .968 \\
\hline 12.5 & .833 & .848 & .856 & .959 & .963 & .962 & .983 & .985 & .982 & .974 & .977 & .969 \\
\hline 13.0 & .833 & .849 & .852 & .962 & .967 & .964 & .979 & .983 & .979 & .972 & .973 & .967 \\
\hline 13.5 & .833 & .848 & .852 & .964 & .970 & .966 & .951 & .962 & .962 & .975 & .962 & .955 \\
\hline 14.0 & .828 & .841 & .846 & .967 & .971 & .966 & .875 & .899 & .910 & .935 & .938 & .935 \\
\hline 14.5 & .814 & .830 & .833 & .965 & .966 & .964 & .809 & .830 & .842 & .893 & .902 & .900 \\
\hline 15.0 & .799 & .813 & .813 & .958 & .955 & .948 & .793 & .804 & .805 & .844 & .852 & .850 \\
\hline
\end{tabular}

TABLE 2. Normal spectral emittance of ceramic oxide specimens

a Average of two readings each on three specimens.

${ }^{b}$ Emittance values low because of error from preferential mirror absorption (sect. 5.1). 


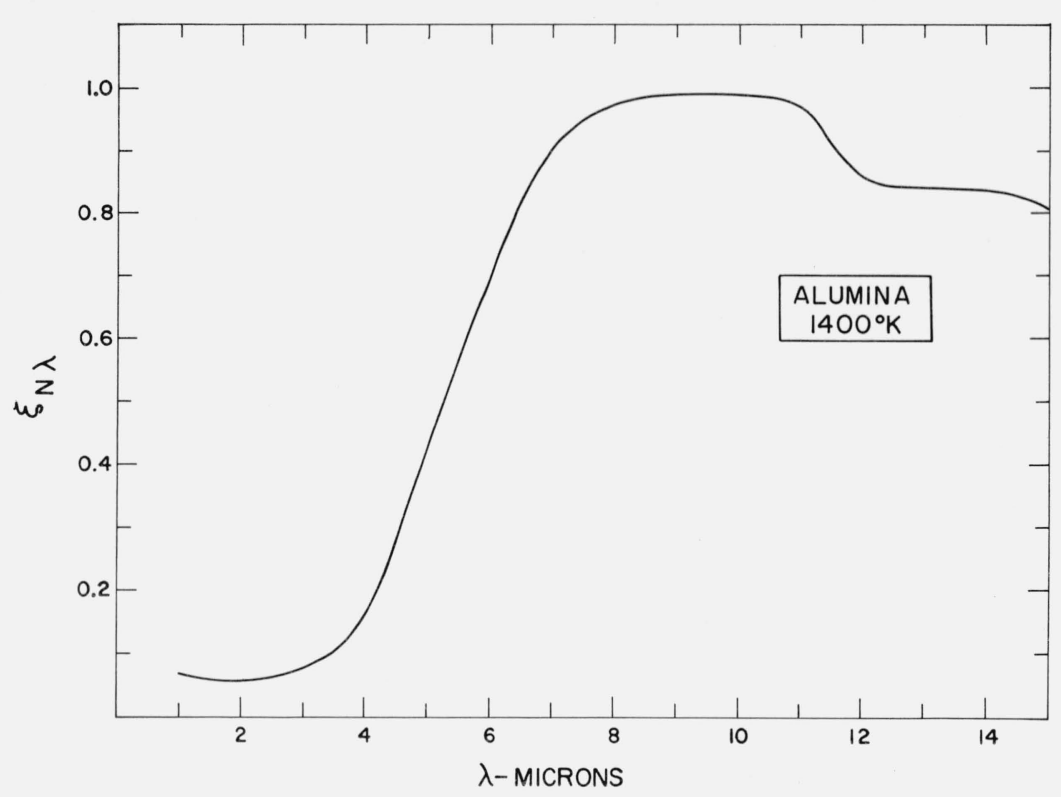

FigURE 10. Normal spectral emittance of commercially pure alumina. Curve represents average from six determinations; two each on three specimens.

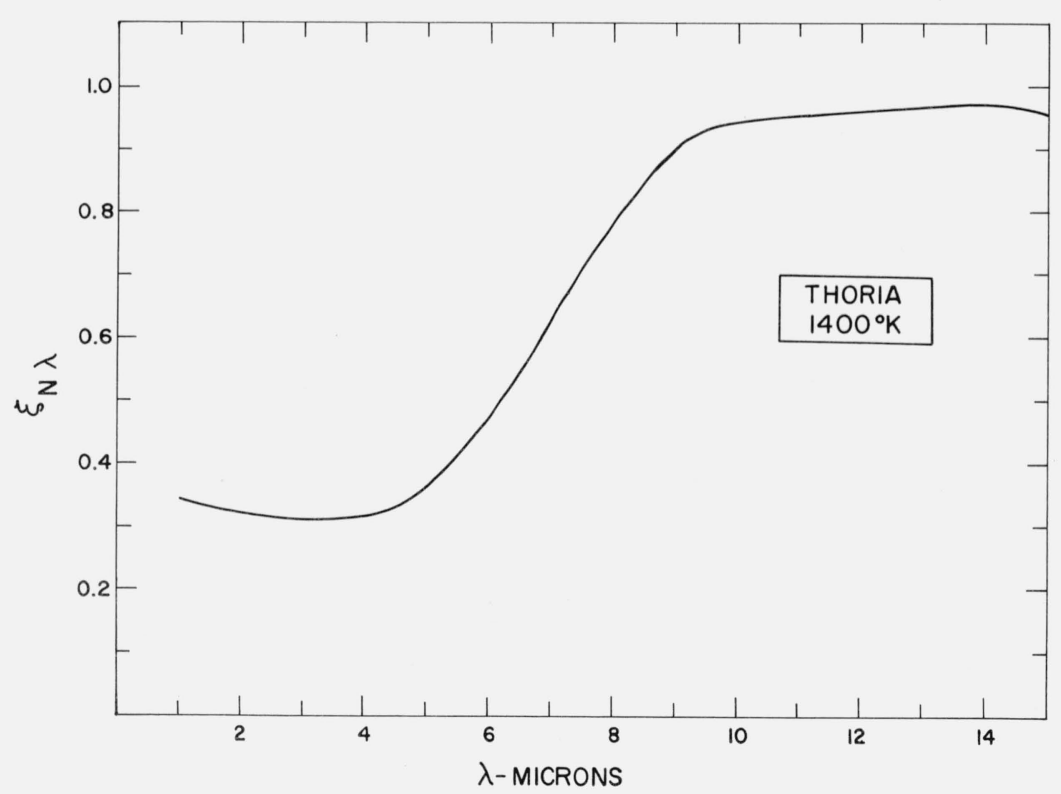

FIGURE 11. Normal spectral emittance of commercially pure thoria. Curve represents average from six determinations; two each on three specimens.

in this report. Also, it is interesting to note that the two standard deviations are related in the following way

$$
S_{\bar{x}}^{2}=\frac{S_{w}^{2}+n S_{b}^{2}}{n}
$$

where $S_{b}$ is the sample estimate of the standard deviation due to differences between specimens.
As shown in table 3 , the values of $S_{w}$ fall in the range 0.001 to 0.021 and are largely independent of temperature. Their magnitude, however, is a function of wavelength, the values being appreciably larger at the short wavelengths than at the long. The values of $S_{\bar{x}}$, on the other hand, are less well behaved due to the manner in which they depend upon differences between specimens. For example, the average value of $S_{\bar{x}}$ is about 0.008 in the wavelength region 1 to $6 \mu$ 


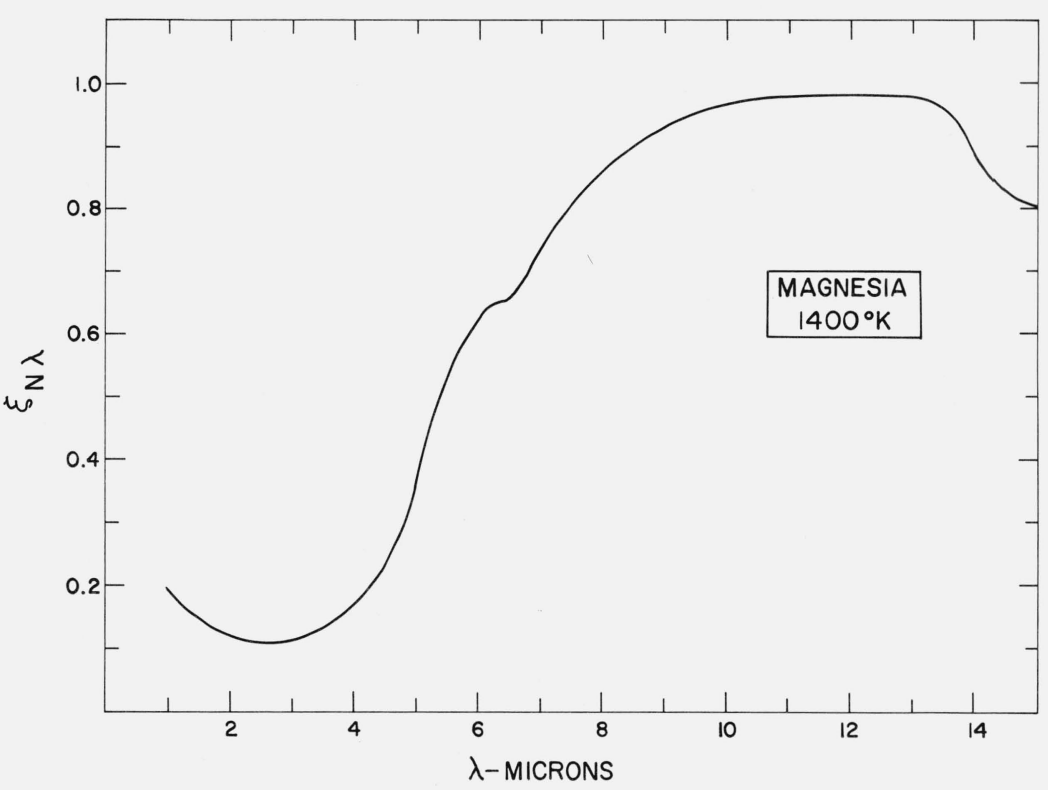

FigURE 12. Normal spectral emittance of commercially pure magnesia. Curve represents average from six determinations; two each on three specimens.



FIGURE 13. Normal spectral emittance of commercially pure, lime-stabilized zirconia. Curve represents average from six determinations; two each on three specimens.

for the alumina, magnesia, and zirconia specimens, but for thoria the average is approximately 0.041 over this same region. Visual examination of the thoria specimens revealed that one of the three $(T-10)$ was darker in color than the other two. This was the same specimen that yielded high emittance in the short wavelength regions. For example, at $2 \mu$ the average emittances from the two determinations on the three thoria specimens were as follows:

\begin{tabular}{|c|c|c|c|}
\hline \multirow[t]{2}{*}{ Spec. No. } & \multicolumn{3}{|c|}{ Ave. $\boldsymbol{\epsilon}_{n \lambda}$ at $2 \mu$} \\
\hline & $1200^{\circ} \mathrm{K}$ & $1400^{\circ} \mathrm{K}$ & $1600^{\circ} \mathrm{K}$ \\
\hline $\begin{array}{l}\mathrm{T}-10 \ldots \\
\mathrm{T}-11 \ldots \\
\mathrm{T}-12 \ldots\end{array}$ & $\begin{array}{r}0.276 \\
.201 \\
.193\end{array}$ & $\begin{array}{r}0.367 \\
.299 \\
.292\end{array}$ & $\begin{array}{r}0.437 \\
.382 \\
.377\end{array}$ \\
\hline
\end{tabular}


TABLE 3. Standard deviations due to error in measurement

\begin{tabular}{|c|c|c|c|c|c|c|c|c|c|c|c|c|}
\hline \multicolumn{13}{|c|}{ Sample estimate, $S_{w}$, of standard deviation due to error in measurement a } \\
\hline Wavelength & \multicolumn{3}{|c|}{ Alumina } & \multicolumn{3}{|c|}{ Thoria } & \multicolumn{3}{|c|}{ Magnesia } & \multicolumn{3}{|c|}{ Zirconia } \\
\hline$\mu$ & 1200 & 1400 & 1600 & 1200 & 1400 & 1600 & 1200 & 1400 & 1600 & 1200 & 1400 & 1600 \\
\hline $\begin{array}{l}1 \\
2 \\
3 \\
4 \\
5\end{array}$ & $\begin{array}{r}0.00376 \\
.00058 \\
.00684 \\
.00689 \\
.00793\end{array}$ & $\begin{array}{r}0.00163 \\
.00372 \\
.01470 \\
.00801 \\
.00696\end{array}$ & $\begin{array}{r}0.00464 \\
.00212 \\
.01390 \\
.00954 \\
.00793\end{array}$ & $\begin{array}{r}0.00582 \\
.00570 \\
.00493 \\
.00777 \\
.00927\end{array}$ & $\begin{array}{r}0.00862 \\
.00404 \\
.00464 \\
.00919 \\
.01099\end{array}$ & $\begin{array}{r}0.00367 \\
.00706 \\
.01173 \\
.01358 \\
.01389\end{array}$ & $\begin{array}{r}0.00141 \\
.00314 \\
.00346 \\
.00671 \\
.00757\end{array}$ & $\begin{array}{r}0.00091 \\
.00319 \\
.00684 \\
.01021 \\
.00933\end{array}$ & $\begin{array}{r}0.00408 \\
.00520 \\
.00890 \\
.01390 \\
.01507\end{array}$ & $\begin{array}{r}0.00780 \\
.01511 \\
.01674 \\
.02071 \\
.01618\end{array}$ & $\begin{array}{r}0.00523 \\
.01185 \\
.01380 \\
.01652 \\
.01363\end{array}$ & $\begin{array}{r}0.00410 \\
.00700 \\
.00889 \\
.01266 \\
.00881\end{array}$ \\
\hline $\begin{array}{r}6 \\
7 \\
8 \\
9 \\
10\end{array}$ & $\begin{array}{l}.00850 \\
.00153 \\
.00091 \\
.00220 \\
.00187\end{array}$ & $\begin{array}{l}.00478 \\
.00289 \\
.00220 \\
.00235 \\
.00242\end{array}$ & $\begin{array}{l}.00635 \\
.00507 \\
.00396 \\
.00449 \\
.00465\end{array}$ & $\begin{array}{l}.01002 \\
.00389 \\
.00534 \\
.00351 \\
.00402\end{array}$ & $\begin{array}{l}.01179 \\
.01797 \\
.00456 \\
.00379 \\
.00361\end{array}$ & $\begin{array}{l}.01488 \\
.00751 \\
.00346 \\
.00416 \\
.00329\end{array}$ & $\begin{array}{l}.00814 \\
.00332 \\
.00297 \\
.00349 \\
.00376\end{array}$ & $\begin{array}{l}.00458 \\
.00615 \\
.00370 \\
.00204 \\
.00300\end{array}$ & $\begin{array}{l}.00751 \\
.00809 \\
.00464 \\
.00238 \\
.00314\end{array}$ & $\begin{array}{l}.01081 \\
.00835 \\
.00292 \\
.00420 \\
.00297\end{array}$ & $\begin{array}{l}.01034 \\
.00523 \\
.00168 \\
.00300 \\
.00204\end{array}$ & $\begin{array}{l}.00498 \\
.00493 \\
.00394 \\
.00204 \\
.00402\end{array}$ \\
\hline $\begin{array}{l}11 \\
12 \\
13 \\
14 \\
15\end{array}$ & $\begin{array}{l}.00277 \\
.00518 \\
.00513 \\
.00670 \\
.00780\end{array}$ & $\begin{array}{l}.00321 \\
.00520 \\
.00451 \\
.00513 \\
.00822\end{array}$ & $\begin{array}{l}.00385 \\
.00486 \\
.00754 \\
.00802 \\
.00883\end{array}$ & $\begin{array}{l}.00406 \\
.00458 \\
.00332 \\
.00389 \\
.00058\end{array}$ & $\begin{array}{l}.00208 \\
.00372 \\
.00351 \\
.00449 \\
.00614\end{array}$ & $\begin{array}{l}.00523 \\
.00274 \\
.00300 \\
.00442 \\
.00890\end{array}$ & $\begin{array}{l}.00332 \\
.00385 \\
.00416 \\
.00574 \\
.00518\end{array}$ & $\begin{array}{l}.00337 \\
.00332 \\
.00321 \\
.00505 \\
.00596\end{array}$ & $\begin{array}{l}.00122 \\
.00231 \\
.00122 \\
.00480 \\
.01122\end{array}$ & $\begin{array}{l}.00422 \\
.00168 \\
.00129 \\
.00071 \\
.00464\end{array}$ & $\begin{array}{l}.00258 \\
.00410 \\
.00311 \\
.00178 \\
.00297\end{array}$ & $\begin{array}{l}.00245 \\
.00306 \\
.00041 \\
.00387 \\
.00367\end{array}$ \\
\hline
\end{tabular}

${ }^{a}$ Each entry corresponds to three degrees of freedom.

TABLE 4. Overall standard deviation

Standard deviation, $S_{\bar{x}}$, dūe to differences between specimens and random error of measurement a

\begin{tabular}{|c|c|c|c|c|c|c|c|c|c|c|c|c|}
\hline \multirow{2}{*}{$\begin{array}{c}\text { Wavelength } \\
\mu\end{array}$} & \multicolumn{3}{|c|}{ Alumina } & \multicolumn{3}{|c|}{ Thoria } & \multicolumn{3}{|c|}{ Magnesia } & \multicolumn{3}{|c|}{ Zirconia } \\
\hline & 1200 & 1400 & 1600 & 1200 & 1400 & 1600 & 1200 & 1400 & 1600 & 1200 & 1400 & 1600 \\
\hline $\begin{array}{l}1 \\
2 \\
3 \\
4 \\
5\end{array}$ & $\begin{array}{r}0.00407 \\
.00486 \\
.00597 \\
.00541 \\
.00937\end{array}$ & $\begin{array}{r}0.00721 \\
.00764 \\
.01169 \\
.01125 \\
.00854\end{array}$ & $\begin{array}{r}0.01077 \\
.01258 \\
.01473 \\
.01136 \\
.00975\end{array}$ & $\begin{array}{r}0.04497 \\
.04612 \\
.04418 \\
.04571 \\
.04258\end{array}$ & $\begin{array}{r}0.03311 \\
.04102 \\
.04526 \\
.04592 \\
.04217\end{array}$ & $\begin{array}{r}0.02943 \\
.03362 \\
.03597 \\
.04024 \\
.03892\end{array}$ & $\begin{array}{r}0.00624 \\
.00300 \\
.00400 \\
.00530 \\
.00624\end{array}$ & $\begin{array}{r}0.00673 \\
.00687 \\
.00776 \\
.01025 \\
.00889\end{array}$ & $\begin{array}{r}0.00757 \\
.00660 \\
.00889 \\
.01159 \\
.01002\end{array}$ & $\begin{array}{r}0.00465 \\
.00553 \\
.00676 \\
.00912 \\
.00879\end{array}$ & $\begin{array}{r}0.00416 \\
.00525 \\
.00633 \\
.00725 \\
.00606\end{array}$ & $\begin{array}{r}0.00679 \\
.00939 \\
.01225 \\
.01334 \\
.01190\end{array}$ \\
\hline $\begin{array}{r}6 \\
7 \\
8 \\
9 \\
10\end{array}$ & $\begin{array}{l}.00705 \\
.00597 \\
.00650 \\
.00375 \\
.00568\end{array}$ & $\begin{array}{l}.00701 \\
.00247 \\
.00475 \\
.00401 \\
.00379\end{array}$ & $\begin{array}{l}.00752 \\
.00626 \\
.00633 \\
.00626 \\
.00425\end{array}$ & $\begin{array}{l}.03744 \\
.02948 \\
.01779 \\
.00275 \\
.00293\end{array}$ & $\begin{array}{l}.03783 \\
.03248 \\
.02019 \\
.00729 \\
.00355\end{array}$ & $\begin{array}{l}.03646 \\
.02980 \\
.01473 \\
.00404 \\
.00325\end{array}$ & $\begin{array}{l}.00407 \\
.00391 \\
.00419 \\
.00401 \\
.00377\end{array}$ & $\begin{array}{l}.00541 \\
.00379 \\
.00650 \\
.00377 \\
.00189\end{array}$ & $\begin{array}{l}.00695 \\
.00486 \\
.00333 \\
.00318 \\
.00300\end{array}$ & $\begin{array}{l}.00621 \\
.00318 \\
.00306 \\
.00150 \\
.00236\end{array}$ & $\begin{array}{l}.00797 \\
.00551 \\
.00362 \\
.00176 \\
.00257\end{array}$ & $\begin{array}{l}.00855 \\
.00525 \\
.00161 \\
.00050 \\
.00132\end{array}$ \\
\hline $\begin{array}{l}11 \\
12 \\
13 \\
14 \\
15\end{array}$ & $\begin{array}{l}.00527 \\
.00454 \\
.00605 \\
.00825 \\
.00813\end{array}$ & $\begin{array}{l}.00425 \\
.00522 \\
.00725 \\
.00759 \\
.00978\end{array}$ & $\begin{array}{l}.00548 \\
.00625 \\
.00737 \\
.00804 \\
.00709\end{array}$ & $\begin{array}{l}.00321 \\
.00444 \\
.00275 \\
.00586 \\
.00391\end{array}$ & $\begin{array}{l}.00180 \\
.00153 \\
.00328 \\
.00225 \\
.00501\end{array}$ & $\begin{array}{l}.00200 \\
.00229 \\
.00257 \\
.00202 \\
.00306\end{array}$ & $\begin{array}{l}.00375 \\
.00506 \\
.00404 \\
.00506 \\
.00501\end{array}$ & $\begin{array}{l}.00306 \\
.00325 \\
.00247 \\
.00701 \\
.00477\end{array}$ & $\begin{array}{l}.00202 \\
.00351 \\
.00278 \\
.00506 \\
.00666\end{array}$ & $\begin{array}{l}.00100 \\
.00029 \\
.00318 \\
.00058 \\
.00350\end{array}$ & $\begin{array}{l}.00153 \\
.00229 \\
.00126 \\
.00321 \\
.00104\end{array}$ & $\begin{array}{l}.00000 \\
.00058 \\
.00293 \\
.00328 \\
.00450\end{array}$ \\
\hline
\end{tabular}

${ }^{\text {a }}$ Each entry corresponds to two degrees of freedom.

At $10 \mu$ and beyond all three thoria specimens were in excellent agreement as indicated by the $S_{\bar{x}}$ values plotted in figure 14. This observation suggests that minor variations in composition can have appreciable effects on the emittance at low wavelengths without causing any significant changes in the longer wavelength region.

\section{c. Lack of Stability of Zirconia Specimens}

The first shipment of zirconia specimens showed poor reproducibility of the emittance curves for repeated determinations on the same specimen. Since the degree of reproducibility seemed to be associated with the time of testing at $1600^{\circ} \mathrm{K}$, a series of hourly measurements was made on a zirconia specimen maintained at that temperature. The emittances were found to progressively increase at the short wavelengths and progressively decrease at the longer wavelengths. The observed changes after $4 \frac{1 / 2}{h r}$ at $1600{ }^{\circ} \mathrm{K}$ are shown in figure 15 . X-ray diffraction patterns made before and after the $1600{ }^{\circ} \mathrm{K}$ treatment showed that the zirconia had become partially destabilized. Before testing the crystal structure was primarily cubic; however, after $5 \mathrm{hr}$ at $1600{ }^{\circ} \mathrm{K}$, the percentage of the monoclinic form had increased by a factor of about three. Thus, although calcium oxide had been added to the zirconia to "stabilize" it as a cubic solid-solution crystal [22], the degree of stabilization actually achieved was inadequate. A later shipment of zirconia showed less significant changes in emittance after a similar test at $1600{ }^{\circ} \mathrm{K}$. The data reported in the tables were obtained with zirconia specimens from the latter shipment. 


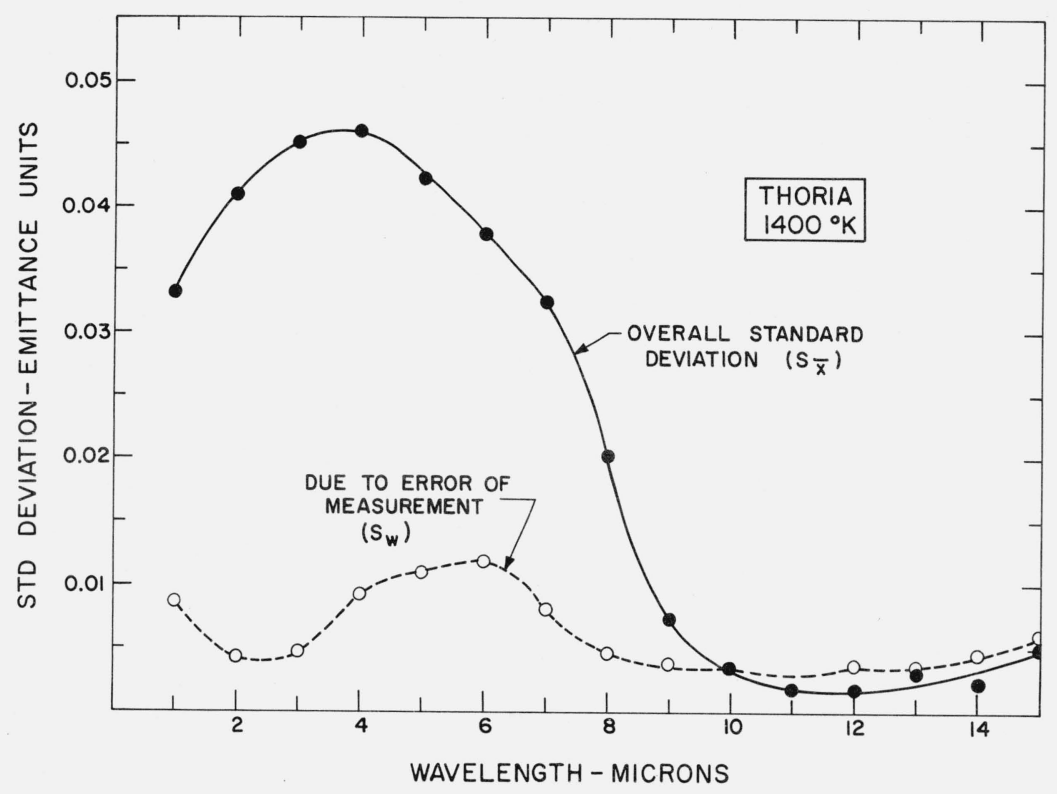

FigURE 14. Standard deviation due to error of measurement $\left(\mathrm{S}_{\mathrm{w}}\right)$ and overall standard deviation $\left(\mathrm{S}_{\overline{\mathrm{x}}}\right)$ for the six thoria determinations.



FigURE 15. Effect of $5 \mathrm{hr}$ heating at $1600^{\circ} \mathrm{K}$ on emittance of poorly stabilized zirconia specimens ( irst lot).

Later shipment did not show this behavior.

\section{d. Effect of Temperature on Emittance}

Inspection of table 2 shows that the emittance of all four materials increases with increasing temperature. As shown in table 5 the magnitude of the increase is much less at the longer wavelengths, where the emittances are high, than at shorter wavelengths where the èmittances are low. In fact, in a few cases at the long wavelengths no measurable change was observed, and for three cases in table 5 a small negative coefficient is reported, although these negative values are not believed to be real. 
TABLE 5. Average increases in emittance per $100^{\circ} \mathrm{K}$ over 1200 to $1600^{\circ} \mathrm{K}$ temperature range

\begin{tabular}{|c|c|c|c|c|}
\hline \multirow{2}{*}{$\begin{array}{l}\text { Wavelength } \\
\text { in microns }\end{array}$} & \multicolumn{4}{|c|}{ Average increase in $\epsilon_{\lambda}$ per $100^{\circ} \mathrm{K}^{\text {a }}$} \\
\hline & Alumina & Thoria & Magnesia & Zirconia \\
\hline 1 & 0.009 & 0.040 & 0.011 & 0.034 \\
\hline 2 & .011 & .044 & .014 & .030 \\
\hline 3 & .010 & .045 & .014 & .027 \\
\hline 4 & .009 & .044 & .014 & .019 \\
\hline 5 & .018 & .033 & .013 & .017 \\
\hline 6 & .016 & .026 & .012 & .012 \\
\hline 7 & .005 & .022 & .016 & .009 \\
\hline 8 & .001 & .015 & .010 & .004 \\
\hline 9 & 0 & .004 & .005 & .002 \\
\hline 10 & 0 & .001 & .001 & .001 \\
\hline 11 & .003 & .002 & .001 & 0 \\
\hline 12 & .009 & .001 & -.001 & -.001 \\
\hline 13 & .005 & 0 & 0 & -.001 \\
\hline 14 & .004 & 0 & .009 & 0 \\
\hline 15 & .004 & -.002 & .003 & .002 \\
\hline
\end{tabular}

${ }^{\text {a }}$ Computed by subtracting emittance at $1200{ }^{\circ} \mathrm{K}$ from emittance at $1600{ }^{\circ} \mathrm{K}$ and dividing by four.

Some metals have been shown to have a negative temperature coefficient of spectral emittance in the very short wavelength regions and a positive coefficient at the longer wavelengths [23]. This means that a "crossover" or " $x$-point" exists in the emittance curves, and at the wavelength of this " $x$-point" the spectral emittance is independent of temperature. Comparison of the rotating-cylinder data for a platinum-13 percent rhodium alloy with other types of measurements made in the same laboratory by other methods [13, 24, 25] strongly suggests that an " $x$ point" exists for this alloy also. This comparison is shown in figure 16.

No such crossover points were observed for the oxide specimens in the particular wavelength and temperature ranges investigated. At the long wavelengths the temperature dependence approaches zero but since the emittances in this region are already above 0.90 , it would obviously be impossible for the emittances to increase by any appreciable extent with temperature.

Figures 17 and 18 compare the changes in emittance with temperature obtained by the rotating-cylinder with those reported by other investigators $[7,26,27$, and 28]. The agreement between the reported values is' better at $10.0 \mu$ than at $2.0 \mu$. At both wavelengths, however, the trend is toward positive coefficients.

For this relatively narrow temperature range the data points obtained from the present measurements are roughly linear with temperature. This relationship can not be expected to apply in general. In fact, it does not even extend downward to room temperature as indicated by the curves plotted in figure 19. The room-temperature $\left(300{ }^{\circ} \mathrm{K}\right)$ points were computed from reflectance measurements made with an ellipsoidal reflectometer that measures absolute reflectance of specimens irrespective of whether they are specular, diffuse, or only partially diffuse in their reflection behavior [24]. The specimens were prepared with the same materials and processing used for the cylinders. Since the measurements were made under near-normal illumination and hemispherical viewing, the reflec-

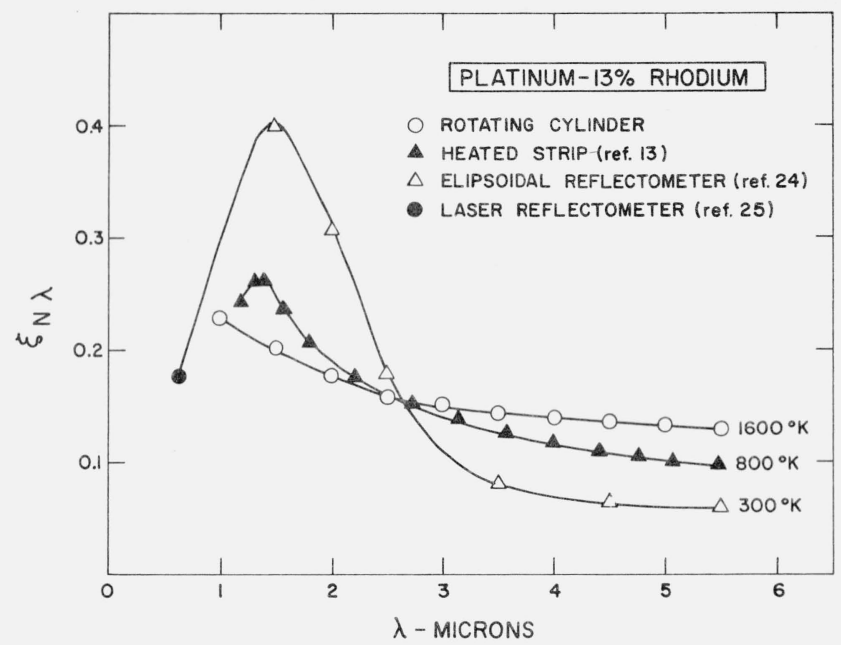

FIGURE 16. Emittances of a platinum-13 percent rhodium alloy at three temperatures.

Determinations by all three methods were made in air on specimens that had been heated for $1 \mathrm{hr}$ at $1850{ }^{\circ} \mathrm{K}$ prior to measurement.

tances can, in accordance with Kirchhoff's law, be converted to spectral normal emittance by subtracting the reflectances from unity. The fact that the points computed from the room-temperature reflectances fall reasonably well in line with the rotating-cylinder points tends to lend credence to both sets of data.

\section{e. Comments on Use of Data for Heat Transfer Computations}

In the past many heat transfer computations have been made with the assumption that the spectral emittance does not change greatly with temperature. The present results indicate that this is not a safe assumption for the polycrystalline oxide materials. Thoria, for example, shows almost a fourfold increase in emittance at $2 \mu$ when the temperature is raised from 300 to $1600{ }^{\circ} \mathrm{K}$. Many more data of this type on temperature dependence are needed before completely reliable heat transfer analyses will be possible. Temperature dependence data for both metals and nonmetals below room temperature are practically nonexistent and emittance data suitable for computing temperature coefficients are notably absent. The reflectance approach has been suggested as a means of obtaining these data because of its potentially greater accuracy $[13,24]$. Much can be said for this approach at low temperatures, but at high temperatures difficulties can be expected because of noise in the signal caused by the high background of radiant flux that is emitted from the specimen. Therefore, it seems likely that at temperatures above about 1200 ${ }^{\circ} \mathrm{K}$, direct measurements of emittance will continue to provide the most reliable data.

The emittances presented in the tables and figures of this report are for specimens of the compositions and structures outlined in section 6.1. Specimens prepared by different processing from materials of different purity, or from materials with different types of impurities, would be expected to show somewhat 


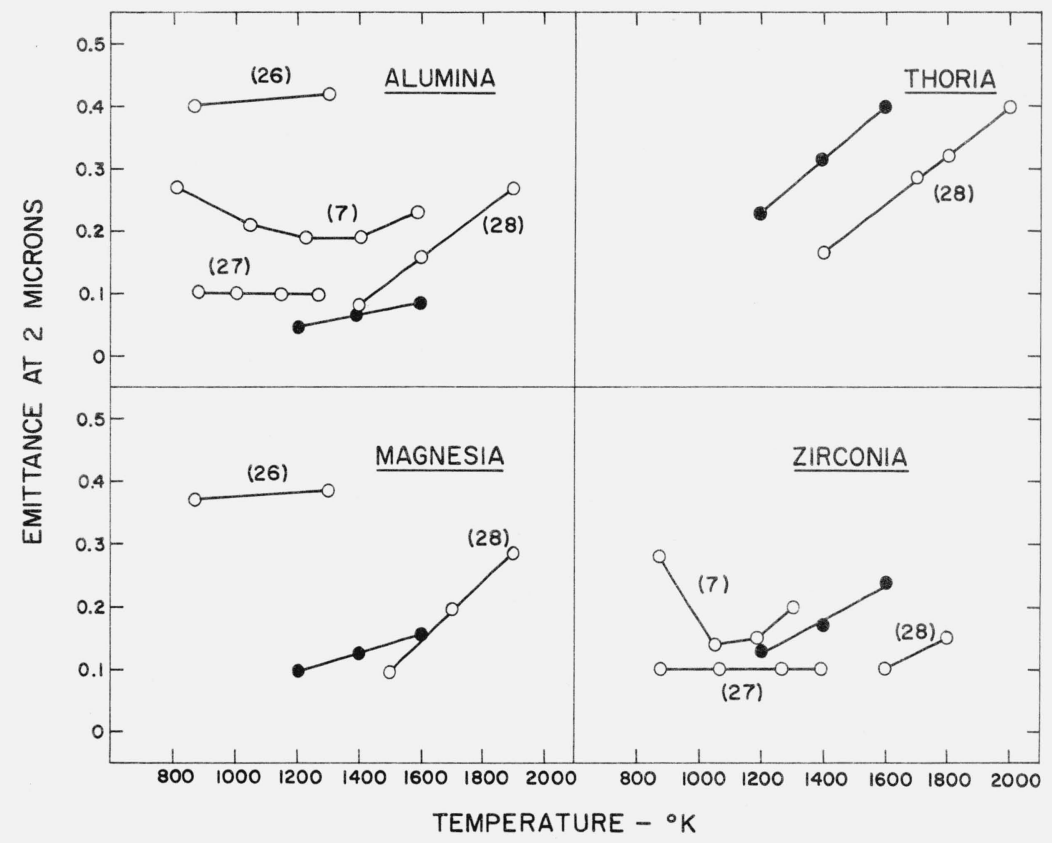

FIGURE 17. Comparison of reported effects of temperature on normal spectral emittance at $2 \mu$.

Source of data is given by reference number in brackets.

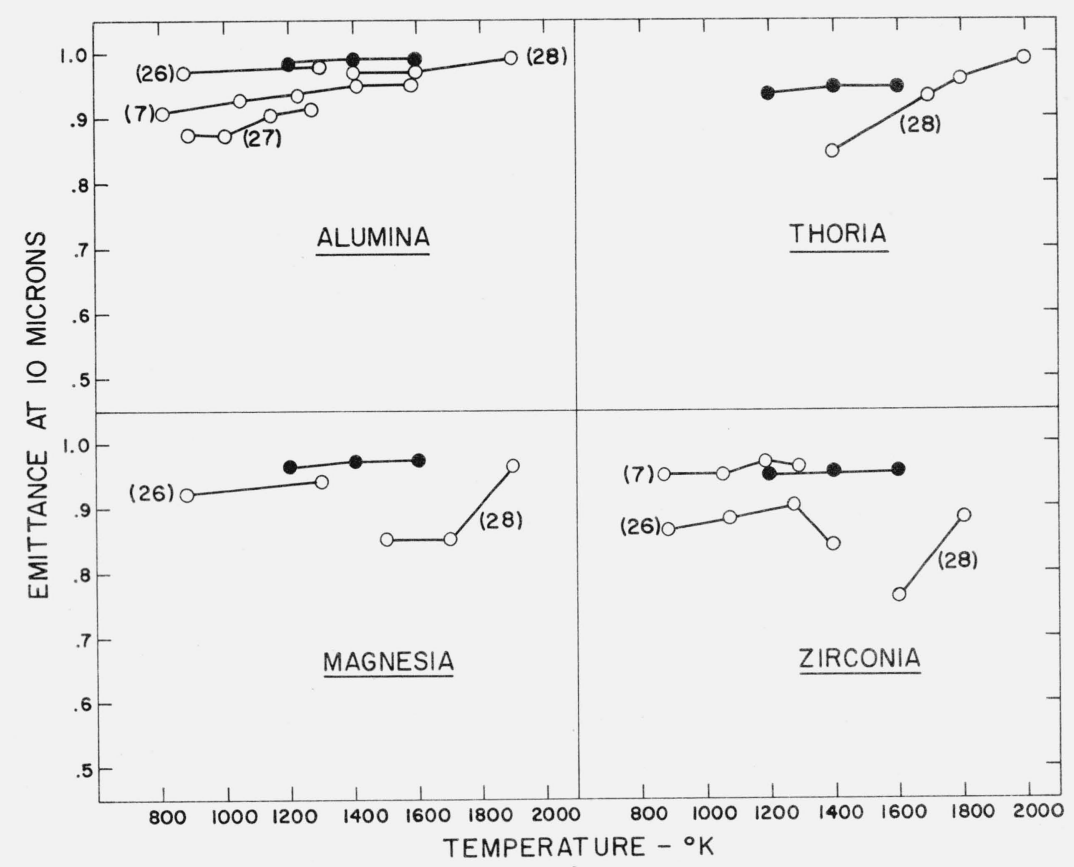

FIGURE 18. Comparison of reported effects of temperature on normal spectral emittance at $10 \mu$.

Source of data is given by reference number in brackets. 


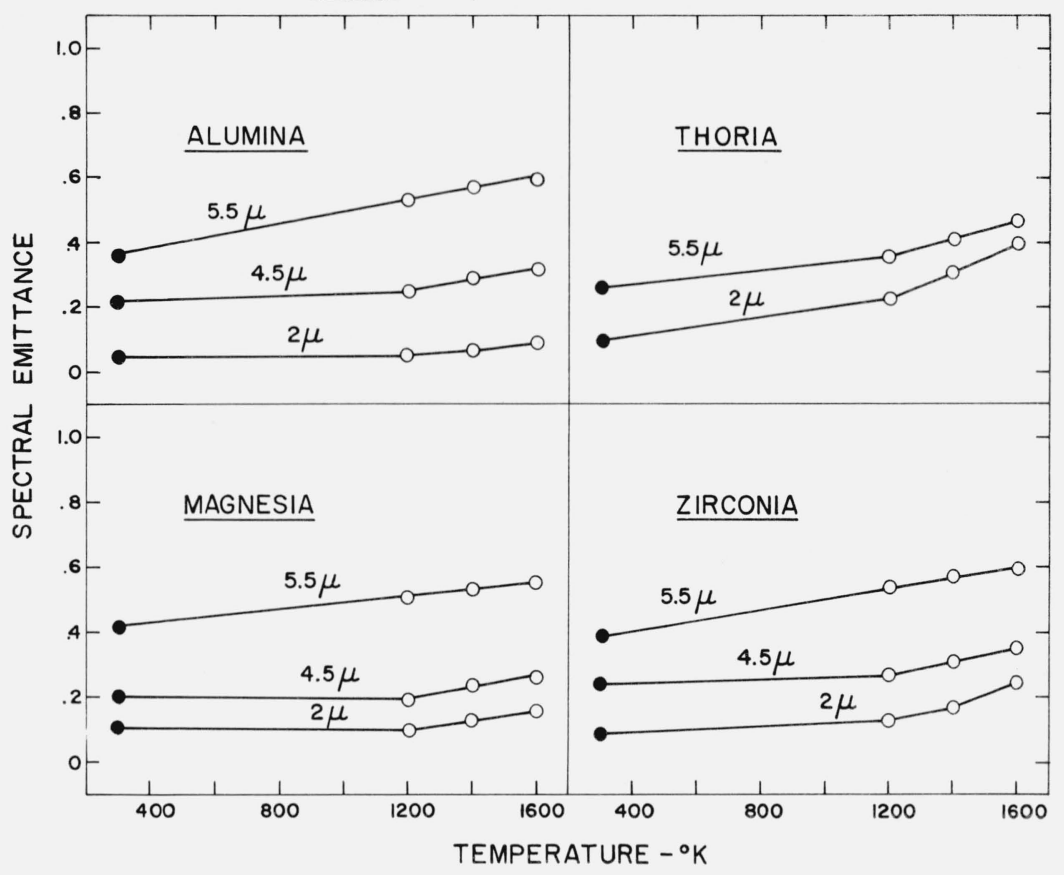

FIGURE 19. Temperature dependence of normal spectral emittance. Open circles are rotating specimen data; closed circles were computed from reflectance data measured with
ellipsoidal mirror reflectometer (reference 24 ).

different emittances, especially in the short wavelength region. For this reason, the emittances as reported herein should not be taken as the emittance of all alumina, thoria, magnesia, or zirconia materials. The only method that will define the thermal radiation properties of any given engineering material is actual measurement by a reliable technique.

Temperature gradients will normally exist in oxide parts used in engineering applications inasmuch as these parts are usually heated in such a way that one or more of the surfaces is free to radiate to ambient. Emittances measured for a specimen with no temperature gradients could of course be used for heat transfer calculations for such parts if the gradients were small. In those cases where the gradients are large, however, the emittances determined for isothermal specimens should be used with caution because of the sizable changes of $\epsilon_{n \lambda}$ with temperature that occur in some wavelength regions (table 3 ).

\section{f. Correlation of Data for Alumina With Reported Absorption Coefficients}

The changes observed in normal spectral emittance, $\epsilon_{n \lambda}$, with both wavelength and. temperature undoubtedly reflect changes that are occurring in the optical properties of the materials. Recently Gryvnak and Burch [29] measured the absorption coefficient of single crystal alumina (sapphire) from room-temperature to the melting point. Figure 20 is copied from their data. It will be noted that the absorption coefficient of sapphire increases with increasing tem-

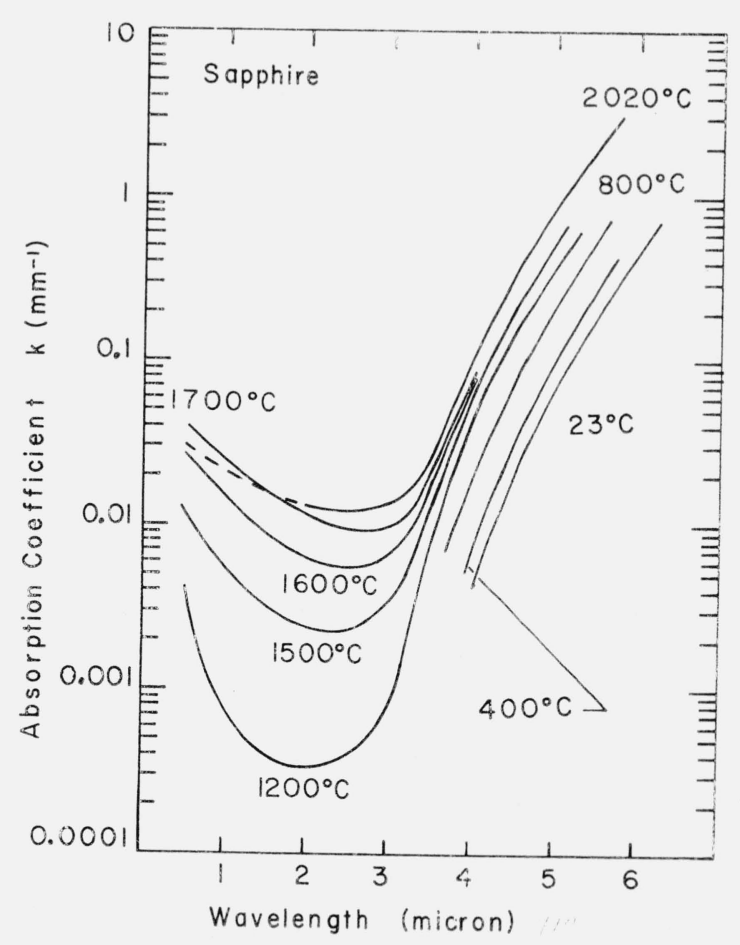

FIGURE 20. Absorption coefficient-wavelength curves for single crystal alumina as reported by Gryvnak and Burch (reference 29). 
perature and that the temperature dependence is greater at the shorter than at the longer wavelengths. The temperature dependence of emittance shows a somewhat similar behavior (table 3 ). This similarity is to be expected since, from a reflectance analogy, as absorption within the material increases the amount of the incident energy that emerges from the surface as reflected energy decreases. Therefore, the reflectance will decrease with increasing absorption coefficient, and the emittance will increase.

Figure 20 shows a dip in the absorption coefflcientwavelength curves in the range 1 to $3 \mu$. As shown in figure 10, a slight dip was also found when $\epsilon_{n \lambda}$, for the polycrystalline alumina, was plotted against wavelength. This dip, however, was not as pronounced for alumina as it was for magnesia (fig. 12), and zirconia (fig. 13).

\section{Summary}

Equipment is described for measurement of the normal spectral emittance of polycrystalline ceramics in the temperature range $1200-1600{ }^{\circ} \mathrm{K}$. Specimens consisted of hollow cylinders that were rotated at $100 \mathrm{rpm}$ in a furnace enclosure before a water-cooled viewing port.

Various sources of error were investigated. The major source was determined to be furnace radiation that was reflected and/or scattered by the specimen into the specimen beam. At $2 \mu$ and $1200^{\circ} \mathrm{K}$, this effect could cause measured values of emittance to be as much as +0.02 higher than the true value. Temperature uncertainties would contribute \pm 0.008 as a maximum while the random error of measurement will be on the order of \pm 0.004 . Thus, the true values of emittance at $2 \dot{\mu}$ and $1200^{\circ} \mathrm{K}$ for the particular specimens measured might be as much as 0.032 lower or 0.012 higher than the reported values.

Measurements were made on commercially pure, polycrystalline specimens of alumina, thoria, magnesia, and zirconia. All showed similar behavior in that the emittance was low in the shorter wavelength regions and high at the longer wavelengths. Over the temperature range investigated the temperature coefficients of spectral emittance were positive for all four materials. The coefficients, however, varied with the material, those for thoria being much higher than for the other three. In all cases coefficients were greater at short wavelengths than at long.

The data were shown to be consistent with those obtained by several other measurement methods and in the case of alumina, the data were consistent with recently reported absorption coefficients for sapphire. Temperature coefficients appeared plausible on the basis of room-temperature reflectance measurements made on the same materials.

The authors gratefully acknowledge the assistance of A. G. Eubanks, who contributed to the solution of some of the early design and construction problems; of J. C. Richmond, for many helpful suggestions on method and procedure; of Francis J. Kelly, who prepared the computer programs for obtaining the standard deviations; and of Dr. David Hogben for guidance in preparing the statistical analysis.

\section{References}

[1]. Féry, C., Ann. Phys. Paris 27, 443 (1902).

[2]. Michaud, M., Silicates Ind. 19, 248 (1954).

[3]. Pattison, J. R., Trans. Brit. Cer. Soc. 54, 698 (1955).

[4]. McMahon, H. O., J. Am. Cer. Soc. 34 (3), 91 (195().

[5]. Slemp, W. S. and Wade, W. R., Sym. on Measurement of Thermal Radiation Properties of Solids, Dayton, Ohio, NASA SP-31, 433 (1963) (available from U.S Govt. Printing Office, Washington, D.C., 20402, \$3.50).

[6]. Olson, O. H. and Katz, S., First Sym. Surface Effects on Spacecraft Materials, Palo Alto, Calif., 164 (1959).

[7]. Folweiler, R. C., Thermal Radiation Characteristics of Transparent, Semi-transparent, and Translucent Materials under Non-Isothermal Conditions, ASD-TDR-62-719 (April, 1964).

[8]. Clayton, W. A., Sym. on Measurement of Thermal Radiation Properties of Solids, Dayton, Ohio, NASA SP-31, 445 (1963), (Available from U.S. Govt. Printing Office, Washington, D.C., 20402, \$3.50).

[9]. Clark, H. E. and Moore, D. G., Equipment for Measuring Thermal Emittance of Ceramic Oxides to $1800{ }^{\circ} \mathrm{K}$, Sym. on Thermal Radiation of Solids, San Francisco, Calif., NASA SP-55, 241 (1965). (Available from U.S. Govt. Printing Office, Washington, D.C., $20402 \$ 3.50$.)

[10]. Peavy, B. A. and Eubanks, A. G., Sym. on Measurement of Thermal Radiation Properties of Solids, Dayton, Ohio, NASA SP-31, 553, (1963). (Available from U.S. Govt. Printing Office, Washington, D.C. 20402, \$3.50.)

[11]. Gouffé, A., Rev. d'Opt. 24, 1 (1945).

[12]. Sanders, C. L. and Stevens, B. A., Rev. d'Opt. 33, 179 (1954).

[13]. Harrison, W. N., Richmond, J. C., Shorten, F. J., and Joseph, H. M., Standardization of Thermal Emittance Measurements, WADC TR-59-510, Pt. IV (Nov. 1963).

[14]. Hass, George and Salzberg, Calvin D., J. Opt. Soc. Am. 44, 181 (1954).

[15]. Clark, H. E., On Avoiding Errors From Stray Radiation in Measuring the Spectral Emittance of Diffusely Reflecting Specimens, J. Appl. Opt. 4, 1356 (1965).

[16]. Richmond, J. C., Radiative Transfer from Solid Materials, 142, ed. H. Blau \& H. Fischer (MacMillan Co., New York, 1962).

[17]. Natrella, M. G., Experimental statistics, National Bureau of Standards Handbook 91, Table A-4 (1963). (Available from USGPO, Wash., D.C. 20402, \$4.25.)

[18]. Gannon, R. E. and Linder, B., J. Am. Cer. Soc. 47,592 (1964).

[19]. Cox, R. L., Fundamentals of Thermal Radiation in Ceramic Materials, Sym. on Thermal Radiation of Solids, San Francisco, Calif., NASA SP-55, 83 (1965). (Available USGPO, Wash., D.C. 20402, \$2.75.)

[20]. Richmond, J. C., Effect of Surface Roughness on Emittance of Non-metals, J. Opt. Soc. Am. 56, 253 (1966).

[21]. Eisenhart, C., Realistic Evaluation of the Precision and Accuracy of Instrument Calibration Systems, J. Res. NBS 67C (Engr. and Inst.) No. 2, 161 (1963).

[22]. Weber, B. C., Garrett, H. J., Mauer, F. A., and Schwartz, M. A., J. Am. Cerm. Soc. 39, 197 (1956).

[23]. Emslie, A. G., A Review of Some Problem Areas in the Theory of Thermal Radiation of Solids, Sym. on Thermal Rad. of Solids, San Francisco, Calif., NASA SP-55, p. 3 (1965). (Available from USGPO, Washington, D.C. 20402 \$2.75.)

[24]. Dunn, S. T., Design and Analysis of an Ellipsoidal Mirror Reflectometer, Ph.D. Thesis, Okla. State Univ., May 1965. (Available from University Microfilms, Inc., Ann Arbor, Mich.)

[25]. DeWitt, D. P. and Richmond, J. C., Design and Calibration of a Laser Source Integrating Sphere Reflectometer. (Presented at Am. Inst. Astr. and Aeronautics Meeting in New York City on Jan. 27, 1965-to be published.) 
[26]. Blau, H. H., Marsh, J. B., Jasperse, J. R., and Chaffee, E. Infrared Spectral Emittance Properties of Solid Materials. AFCRL TR-60-416 (Oct. 1960).

[27]. Schatz, E. A., Counts, C. R. and Burks, T. L., Coatings for Energy Utilization, Control, and Protective Functions, AFML ML TDR 64-146 (1964).

[28]. Ritzow, G., Ann. der Physik 19, 769 (1934).

[29]. Gryvnak, D. A. and Burch, D. E., Optical and Infrared Properties of $\mathrm{Al}_{2} \mathrm{O}_{3}$ at Elevated Temperatures. J. Opt. Soc. Am. 55, 625 (1965).

\section{Appendix A. Analysis of Error Caused by Nonisothermal Blackbody Furnace}

Consider a cylindrical blackbody furnace cavity, whose back wall is maintained at $1200{ }^{\circ} \mathrm{K}$ and whose sides are at $1225^{\circ} \mathrm{K}$. Further, assume that the cavity is constructed of an opaque material with an emittance $\epsilon_{\lambda}$ of 0.50 at all wavelengths. As a first approximation, the energy radiated along the axis of the cavity will consist of two components, an emitted component, $\epsilon_{\lambda} W\left(\lambda, T_{b}\right)$, and a reflected component, $\rho_{\lambda} W\left(\lambda, T_{s}\right)$, where $W(\lambda, T)$ is Planck's expression for the energy radiated by a blackbody at temperature $T$. $\mathrm{T}_{b}$ is the temperature of the back wall, and $T_{s}$ is the temperature of the sides. Since the reflectance of the back wall will be $\rho_{\lambda}=1-\epsilon_{\lambda}$, its reflectance will be 0.50 . One can then write for the energy distribution of radiant flux, $W_{\lambda}$

$$
\begin{aligned}
W_{\lambda} & =0.50 W\left(\lambda, T_{b}\right)+0.50 W\left(\lambda, T_{s}\right) \\
& =0.50 W\left(\lambda, 1200^{\circ} \mathrm{K}\right)+0.50 W\left(\lambda, 1225^{\circ} \mathrm{K}\right)
\end{aligned}
$$

When an optical pyrometer is sighted on the furnace opening, as was done in the present measurements, the indicated temperature, $T^{\prime}$, at $\lambda=0.65 \mu$ is assumed to be that of a perfect blackbody. Thus, one can write:

$$
\begin{aligned}
W\left(0.65 \mu, T^{\prime}\right)=0.50 W( & \left.0.65 \mu, 1200^{\circ} \mathrm{K}\right) \\
+ & 0.50 W\left(0.65 \mu, 1225^{\circ} \mathrm{K}\right) .
\end{aligned}
$$

The error $E_{\lambda}$ introduced by assuming that the nonisothermal furnace can be approximated by a perfect blackbody at the optical temperature $T^{\prime}$ is

$$
E_{\lambda}(\%)=\frac{W{ }_{\lambda}-W\left(\lambda, T^{\prime}\right)}{W_{\lambda}} \times 100 .
$$

A computer program, prepared to calculate $T^{\prime}$ and $E_{\lambda}$ at $0.25 \mu$ intervals over the range 1 to $15 \mu$, showed a maximum error of only 0.44 percent. This occurred at a wavelength of $1.25 \mu$. At $10 \mu$ the error is only 0.14 percent.

The blackbody furnaces used in this investigation had gradients less severe than those assumed in the calculation, and the emittance of the actual cavity walls is significantly higher than 0.50 . Thus, the energy radiated along the axis of the laboratory furnaces should even more closely approximate blackbody radiation. At higher temperatures, 1400 and 1600 ${ }^{\circ} \mathrm{K}$, the Planck Function $W(\lambda, T)$ is less sensitive to temperature differences, and the measured gradients are smaller, so that the errors will be even less significant than at $1200^{\circ} \mathrm{K}$.

(Paper 70A5-412) 